\title{
The role of radiography in the study of spinal disorders
}

\author{
Fernando Ruiz Santiago ${ }^{1}$, Antonio Jesús Láinez Ramos-Bossini ${ }^{1}$, Yì Xiáng J. Wáng ${ }^{2}$, Daniel López Zúñiga ${ }^{1}$ \\ ${ }^{1}$ Department of Radiology, Neuro-traumatology Hospital, Hospital Virgen de las Nieves, University of Granada, Granada, Spain; ${ }^{2}$ Department \\ of Imaging and Interventional Radiology, the Chinese University of Hong Kong, Prince of Wales Hospital, Shatin, New Territories, Hong Kong, \\ China
}

Correspondence to: Fernando Ruiz Santiago. Department of Radiology, Neuro-traumatology Hospital, Hospital Virgen de las Nieves, University of Granada, C-Julio Verne 8, 7 B, 18003 Granada, Spain. Email: ferusan12@gmail.com.

\begin{abstract}
Despite the growing use of computed tomography (CT) and magnetic resonance imaging (MRI) in the study of spinal disorders, radiography still plays an important role in many conditions affecting the spine. However, the study and interpretation of spine radiograph is receiving less attention and radiologists are increasingly unfamiliar with the typical findings in normal and pathologic conditions of the spine. The aim of this article is to review the radiologic indications of radiograph in different pathologic conditions that affect the spine, including congenital, traumatic, degenerative, inflammatory, infectious and tumour disorders, as well as their main radiographic manifestations.
\end{abstract}

Keywords: Spine; radiography; back pain; spinal disorder; spinal curvature; osteoporotic fracture

Submitted May 05, 2020. Accepted for publication Aug 31, 2020.

doi: 10.21037/qims-20-1014

View this article at: http://dx.doi.org/10.21037/qims-20-1014

\section{Introduction}

The simplest and most accessible technique in the department of radiology is conventional radiography. Paradoxically, clinicians and radiologists are losing their interest in interpreting radiographs, relying more in the source of information provided by tomographic techniques, such as computed tomography (CT) and magnetic resonance imaging (MRI). Although radiography in the digital format remains as one of the most frequently employed techniques in the study of spinal pain, both its role and importance have greatly changed with the widespread use of CT and MRI.

Because CT and MRI have displaced radiography in the study of many spinal conditions, radiographic signs of spinal conditions have become increasingly less studied and thus less known among clinicians and radiologists. The aim of this narrative review is to review the diagnostic findings that radiography may provide in the study of spinal disorders and their role in patient management.

\section{General indications for spine radiographs}

Leaving aside extraspinal causes, the most frequent origin of spinal pain is classified as "non-specific" (70\%) because the specific nociceptive source cannot be identified, although it is supposedly related to sprain and/or strain of the soft tissues (1). In this setting, no imaging studies are recommended (2). Mechanical back pain is considered the second most prevalent cause $(27 \%)$ and includes degenerative disorders of the spine, alignment abnormalities and vertebral fractures. In this case, radiographs are recommended as the initial imaging study in patients with history of low-energy trauma and in patients with suspicion of vertebral compression fracture, such as osteoporotic patients or those receiving steroids. Flexion and extension radiographs may also be useful in assessing spinal stability. Finally, back pain may be secondary to specific causes, such as infection, inflammatory or tumor conditions; in this group, radiographs are still recommended to evaluate young patients for ankylosing spondylitis (3). 
In children with back pain, algorithms have been developed to avoid unnecessary radiation exposure $(4,5)$. As with adults, non-specific pain is the most common cause of back pain. Therefore, in pain of short duration and no red flags, no imaging is indicated (5). When persistent pain or red flags are present (e.g., fever, trauma, history of malignancy), radiography is still considered the first imaging modality. In some reported studies, radiograph demonstrated abnormalities in approximately $8-13 \%$ of paediatric patients with back pain (5-7). However, in patients with an underlying pathology confirmed by other imaging methods, radiographs showed abnormalities in $26-76 \%$ of cases, helping therapy guidance or directing further imaging studies (6-8). The most common diagnoses are spondylolysis, spondylolisthesis, Scheuermann's kyphosis, indirect signs of disc pathology, infectious and neoplastic conditions $(5,7)$. Anterior-posterior and lateral radiographs showed a sensitivity of $77.6 \%$ for the detection of spondylolysis (9). Radiographs also play a key role in the diagnosis and management of abnormal spine curvature, including scoliosis and kyphosis. Regarding disc pathology, radiography is not sensitive to early changes or disc displacement. Studies using MRI reported a greater frequency of disc pathology undetected by radiography in children (5). Finally, when specific causes of back pain (e.g., tumour or infection) are suspected, radiographs have low sensitivity and can often miss subtle findings (6). If the clinical history, physical examination, and radiographs do not lead to any specific diagnosis, MRI is advocated as the next diagnostic exam because of its high sensitivity to depict the spinal and paraspinal soft tissues, disc and vertebral abnormalities associated to back pain (5).

\section{Congenital pathology}

Congenital alterations of the spine can be simple, when there is no associated spinal deformity or have little or no clinical consequence, or complex, when associated with serious deformities such as kyphosis, lordosis or scoliosis, or have neurologic implications (10). Congenital vertebral anomalies can be secondary to defects involving vertebral formation, vertebral segmentation or both (11). In the first case, all or part of the vertebra is not well formed/developed, leading to deformities such as agenesis, hemivertebrae, wedged or butterfly vertebrae (Figure 1). In the second case, the embryonic vertebrae are not separated resulting in congenital vertebral block formation. Typical signs that allow differentiation of congenital from acquired vertebral block are the preservation of normal vertebral height of the affected vertebral bodies and the narrow waist of the union between both vertebrae, due to the lack of formation or development of the epiphysial rings at the level of the absent disc. This is known as the wasp-waist sign (12). Combined cases include complex congenital syndromes such as KlippelFeil, Jarcho-Levin, or Goldenhar, etc. $(13,14)$ (Figure 1).

Among patients with congenital spine deformities, $80 \%$ had a scoliosis, $14 \%$ had a kyphoscoliosis, and $6 \%$ had a pure kyphosis. Hemivertebra is the most common cause of a congenital scoliosis followed by unilateral unsegmented bar. An anterior failure of vertebral body formation is the most common cause of congenital kyphosis or kyphoscoliosis (11). It has been classified into posterolateral quadrant vertebra (35\%), posterior hemivertebra (7\%), butterfly vertebra $(13 \%)$ and anterior wedged vertebrae (5\%) (15).

Radiography is usually the first imaging method to study congenital vertebral abnormalities and related deformities, allowing their classification, evaluation of severity and assessment of risk of progression (16). As the number of bony malformations increases, there is a higher incidence of cord anomalies ranging from $20 \%$ to $58 \%$ (16-18) and being greater in the presence of combined failures of segmentation and formation (18). MRI is the appropriate technique for complete evaluation of intraspinal abnormalities. CT may also be useful in defining the anatomy of vertebral deformities in presurgical planning (19).

Among the simple congenital abnormalities, transitional vertebra is considered a developmental variance that is present in $<25 \%$ of the population (20-22) (Figure 2). The most frequent presentation (around 17\% of the cases) is sacralisation of L5 which is fused to the sacrum, followed by lumbarisation (around 2\% of the cases), in which $\mathrm{S} 1$ is detached from the sacrum. Radiographs of the entire spine, if available, allow the radiologist not only to count vertebral bodies from C2 down, but also to differentiate hypoplastic ribs from lumbar transverse processes (21). In our clinical practice in Granada, Spain, we frequently use both, the AP radiograph of the chest and the radiograph of the lumbar spine, to achieve the same purpose. Identification of the correct vertebral level is essential when spinal surgery is planned (22). The association between transitional vertebra and lumbar pain, i.e., Bertolotti syndrome, is controversial, but there is more consensus on the higher prevalence of degenerative changes of the disc and facet joints at the superior level of the transitional vertebra, as a consequence of the increased stress at the closest mobile segment to the 

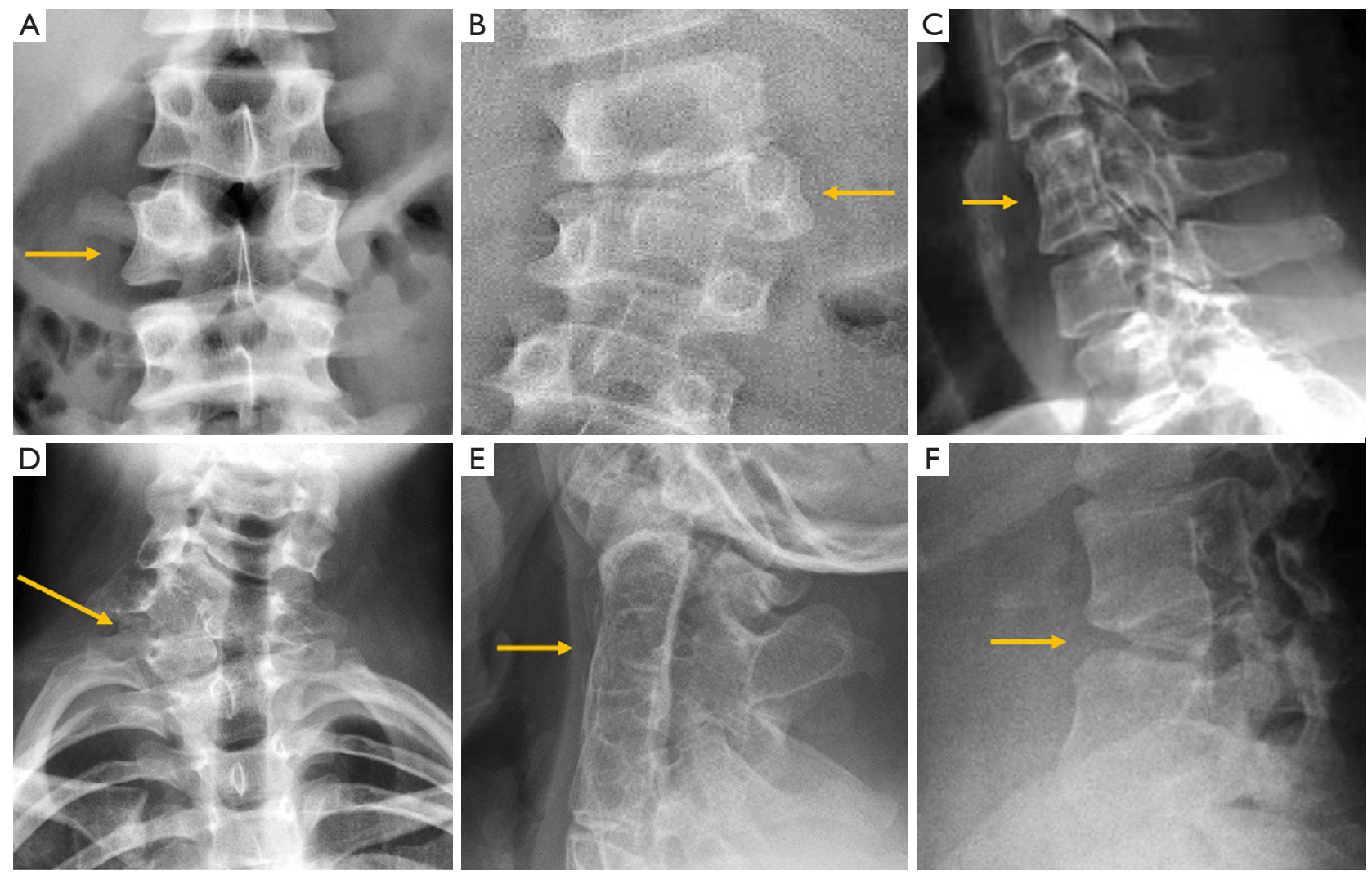

Figure 1 Congenital abnormalities in different patients. (A) Butterfly vertebra; (B) hemivertebra; (C) vertebral block. Complex abnormalities in Klippel Feil (D) and Jarcho-Levin (E) syndromes. (F) Kyphotic deformity secondary to anterior failure of vertebral body formation. Arrows point the main abnormality in each case.

fused transitional vertebral (22).

Transitional anomalies can also affect the cervicothoracic junction. Cervical ribs are the most frequent transitional abnormality and have been described associated with lumbar sacralization. Another less well-known transitional anomaly is the elongation of the anterior tubercle of the cervical transverse process, which may lead to fusion between two vertebrae, typically between C5 and C6 (23) (Figure 2).

\section{Traumatic pathology}

Radiographs have largely been superseded by CT for the assessment of traumatic cervical spine injury (24). The sensitivity of radiographs compared with CT ranges from $36 \%$ to $65 \%(25,26)$. Therefore, most guidelines recommend $\mathrm{CT}$ as the initial radiological examination when traumatic injury to the cervical spine is suspected, preserving MRI for selected cases with neurological compromise or ligament injury $(6,27,28)$.
Imaging of the cervical spine is indicated if the patient meets at least one of the 5 criteria of the National Emergency X-Radiography Utilization Study (NEXUS), developed with data from 21 centres across the United States (29). The more complex Canadian C-Spine Rule (CCR) clinical criteria can also be used to determine the need for imaging in cervical spine trauma (30).

Despite the many advantages of CT, in hemodynamically stable patients, radiographs may be appropriate in some clinical scenarios and in low risk patients $(6,31)$ to guide in pre-operative planning or follow-up control after medical or surgical treatment. Therefore, interpreting radiographs in the context of traumatic cervical spine is still important for radiologists. The lateral radiograph is the most important view in this context, and interpreting it correctly helps to elucidate bone anatomy and alignment (Figure 3). When examining a lateral radiograph of the cervical spine, there are 5 lines that should be observed to rule out spinal fracture or dislocation. From front to back, these correspond to the 

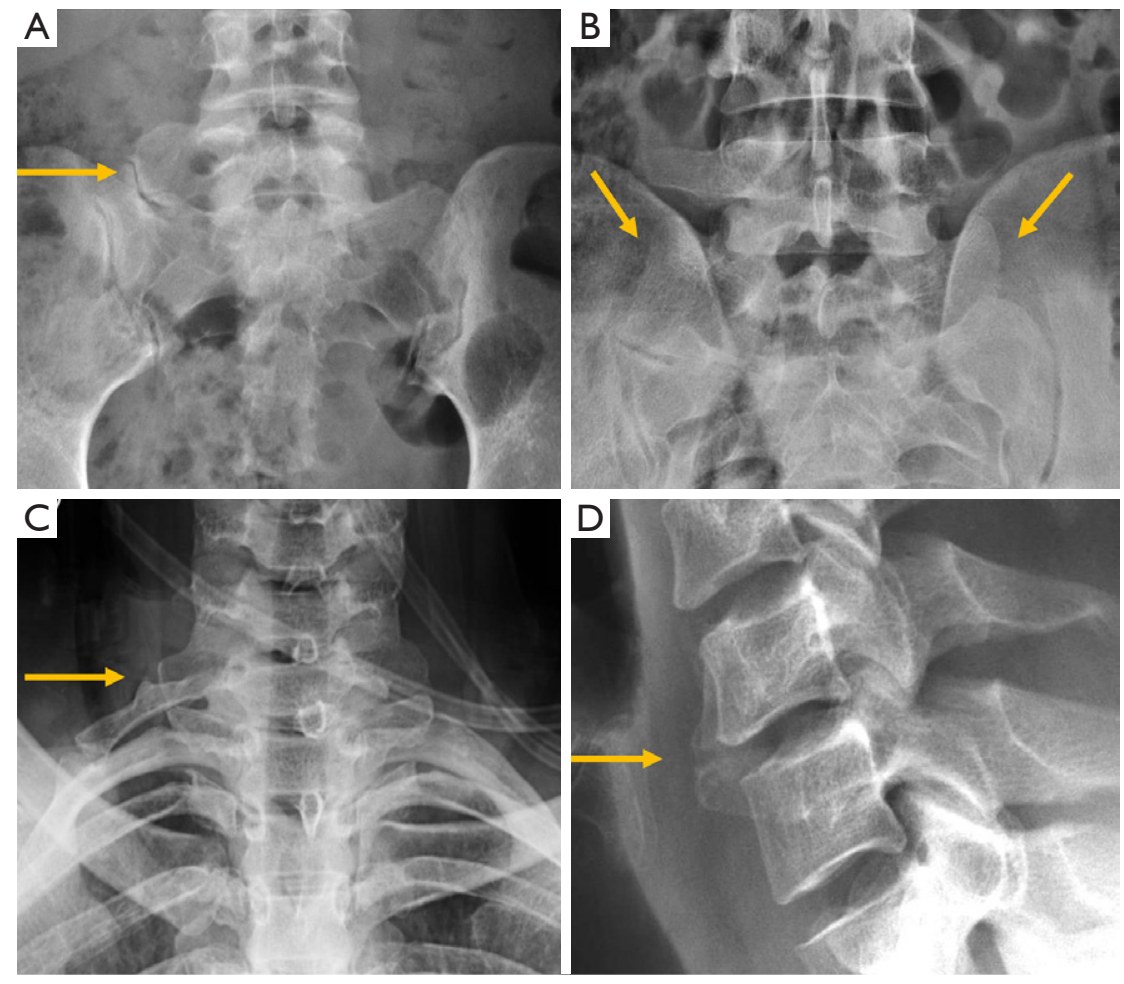

Figure 2 Transitional abnormalities in different patients. (A) Sacralisation; (B) lumbarisation; (C) cervical rib; (D) elongation of the anterior tubercle of the cervical vertebral transverse process. Arrows point the main abnormality in each case.

prevertebral soft tissues, the anterior vertebral, the posterior vertebral, the spinolaminar and the supraspinous lines. Notably, disruption of the posterior vertebral line has the greatest clinical implications due to its proximity to the spinal cord (Figure 3). Also, on a well-positioned lateral radiograph, the anterior arch of the normal atlas shows a crescent shape. Finally, the utility of flexion and extension films to evaluate ligamentous injury is debatable but is still employed in a significant number of trauma centres to diagnose posttraumatic instability (31). Nevertheless, the routine and selective use of functional radiographs is questionable as pathological findings are rare (32).

In traumatic thoracolumbar fractures, the reported sensitivity of radiographs ranges from $49 \%$ to $62 \%$ at the thoracic level and from $67 \%$ to $82 \%$ at the lumbar level (33-35). In addition, the severity of vertebral fractures may be underrated in radiographs, with up to $25 \%$ of burst fractures misdiagnosed as wedge compression fractures (36). Therefore, CT must be performed even after detection of a vertebral fracture in radiographs for proper grading. Nevertheless, it is important to be aware of the radiological signs that allow the diagnosis and grading of severity of traumatic fractures, mainly because there is no current universal availability of CT or MRI and thus radiologists may have to deal with radiographs of trauma patients in an emergency setting. A vertebral fracture is considered as a burst fracture when the posterior vertebral wall is affected. Signs associated with severity and instability of burst fractures include widening of the interpedicular distance, widening of the interspinous distance (manifested in AP radiographs as the "empty vertebra" sign) and the presence of horizontal fracture in the pedicles (Figure 4).

\section{Osteoporotic vertebral fracture (OVF)}

Osteoporosis is a systemic skeletal disease characterised by a reduction in bone mass and qualitative skeletal changes (macro- and microarchitecture, material properties, geometry, and micro-damage) leading to increased bone fragility and fracture risk. There are two forms of the disease: (I) primary osteoporosis, which includes juvenile, postmenopausal, and male and senile osteoporosis; and (II) secondary osteoporosis, which is caused by a large number of diseases and medications. Fragility fractures may occur in 

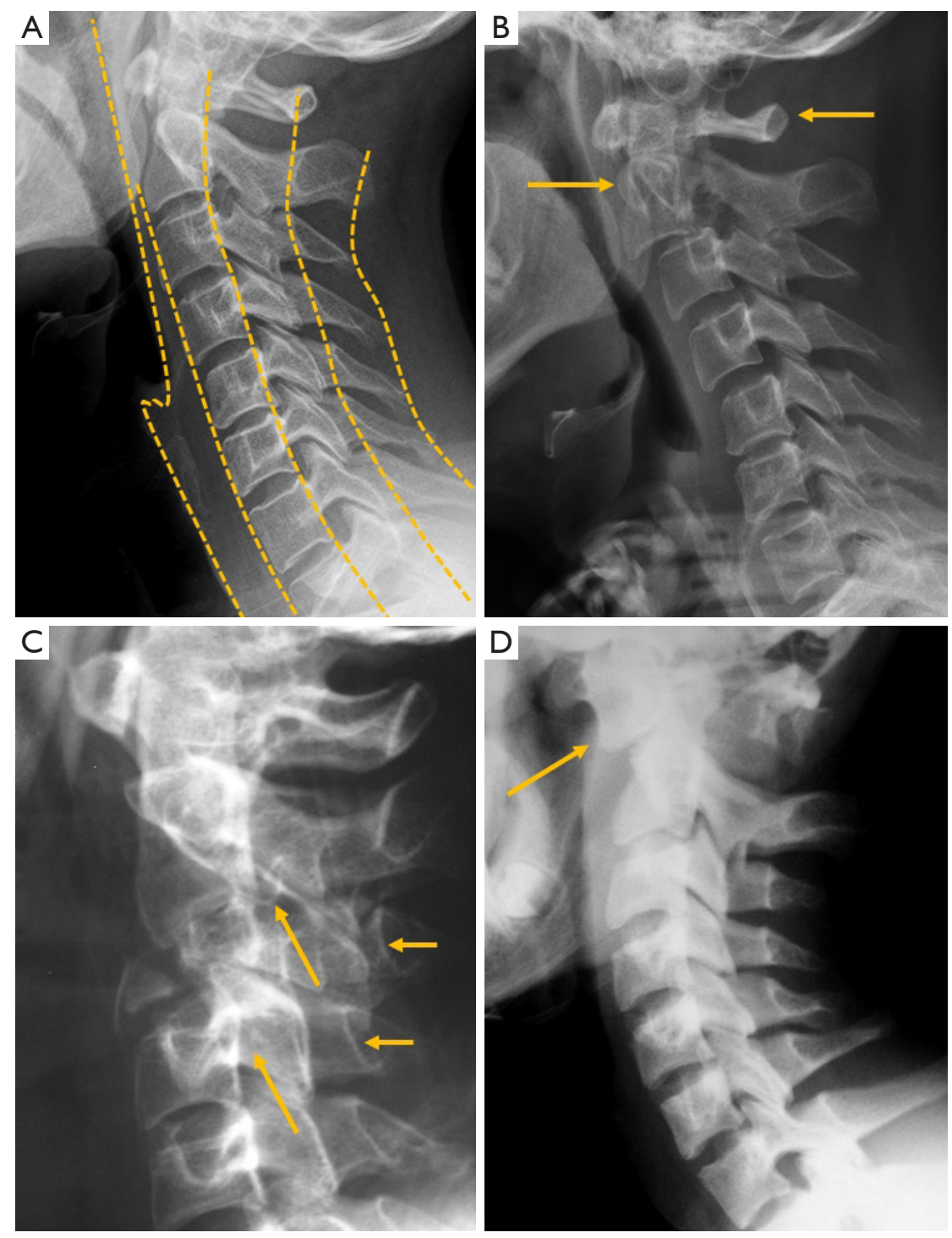

Figure 3 Traumatic pathology of the cervical spine. (A) The 5 normal lines to check in lateral radiographs of the cervical spine; (B) the same patient of A after a car crash suffered a fracture of the $\mathrm{C} 2$ pedicles (hangman's fracture) and radiography shows the anterior displacement of the C2 vertebral body and atlas (arrows); (C) C3 burst fracture with disruption of the posterior vertebral and spinolaminar lines (arrows); (D) lateral radiographs showing loss of the normal crescent shape of the anterior arc of the atlas in a patient with rotatory subluxation of the atlas (arrow).

almost all skeletal segments, but the preferential locations are the vertebral column, the proximal ends of the femur and humerus, and the distal end of the radius (Colles fracture). Trauma due to a fall is by far the most frequent cause of fractures affecting long bones (femur, humerus, and radius), while it is more difficult to determine the cause and the exact time of fragility fractures of the vertebral body, which often go undiagnosed. OVF has high prevalence in the elderly population. It affects at least one-fourth of all postmenopausal women, and is commonly seen among women approximately one decade after menopause (37). It is estimated that the prevalence of OVF in elderly men is approximately half of that in age matched women (38). A vertebral fracture, after minor trauma, is a hallmark of osteoporosis.

The detection of OVF in women suggests that the patient's bone strength is compromised, and the risk of future fracture is substantially increased, both for further OVFs and non-vertebral fragility fractures including the hip (39-43). 

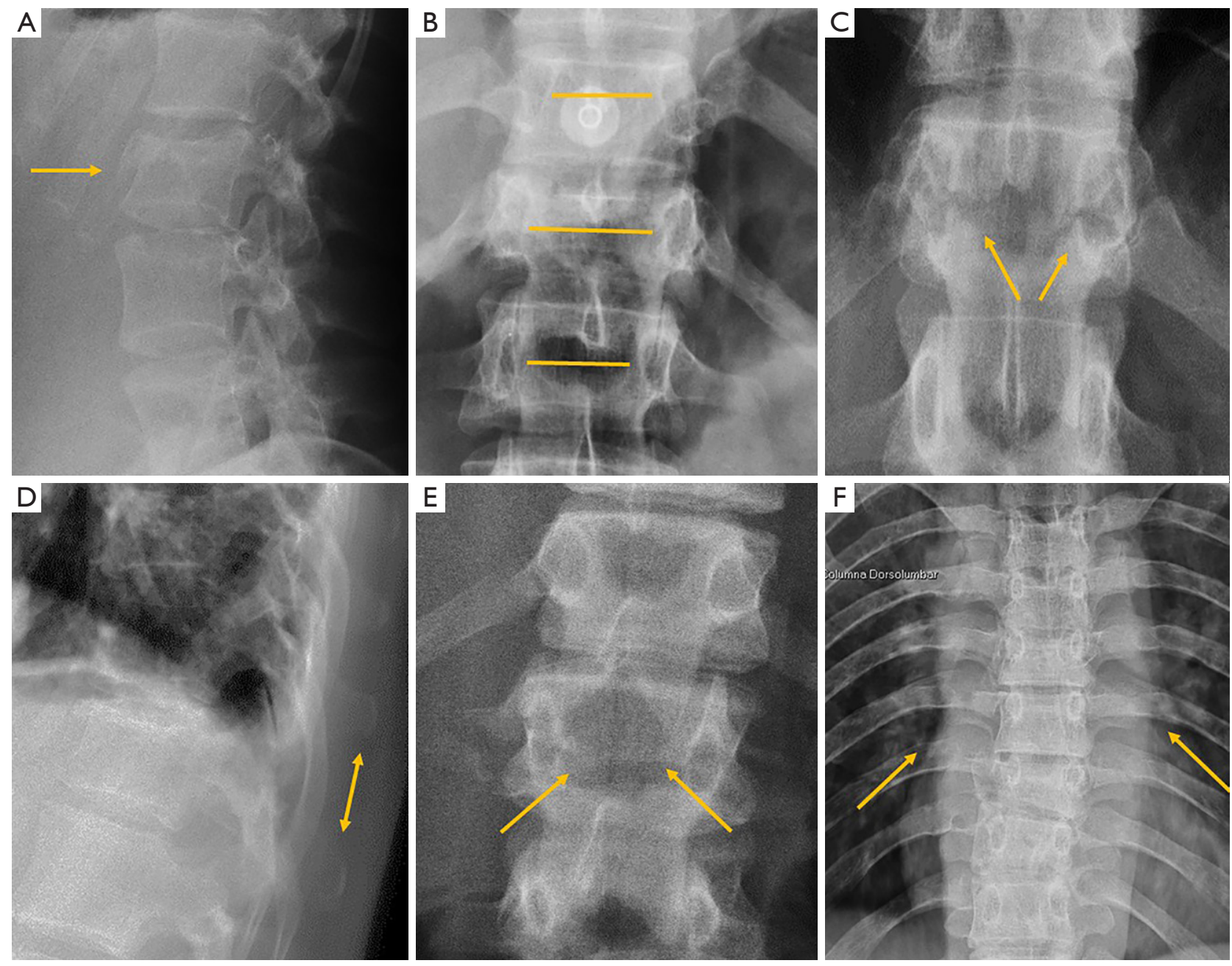

Figure 4 Traumatic pathology of the thoracolumbar spine. (A) Post-traumatic wedge compression fracture; (B) increased interpedicular distance in burst fracture; (C) horizontal fracture through the pedicles; (D) increased interspinous distance; (E) empty vertebra sign; (F) paravertebral haematoma. Arrows point the main abnormality in each case.

OVFs can be associated with decreased trunk extension torque, spinal motion, functional reach, mobility skills and walking distance, and may also influence mortality because of their association with chronic back pain, immobility and postural change $(38,41,43)$. Multiple and more severe grades of OVFs are associated with an even greater fracture risk (41-43). Hip fractures have highly detrimental and very costly individual and social repercussions, and in women over 55 years and older, they are responsible for more hospitalisations than heart attacks, strokes, and breast cancer combined (44). Advances in understanding the biology of osteoporosis have resulted in several medications that have been demonstrated to reduce fracture risk $(45,46)$. Nonpharmacologic approaches to manage osteoporosis, including adequate calcium and vitamin D intake and physical activity, can positively affect bone mass. Coupled with preventing falls and limiting modifiable risk factors, such as smoking and alcohol use, these measures can help reduce the risk for osteoporotic fractures $(41,43)$.

OVF may often be relatively asymptomatic. In the MrOS (USA) follow-up study, Ensrud et al. (47) reported that $13.5 \%$ of incident radiographic OVFs in elderly men were also clinically diagnosed as incident fractures. In postmenopausal women included in the Fracture Intervention Trial Research study, Fink et al. (48) reported that about $25 \%$ of incident radiographic OVFs were also diagnosed as clinical VF in women. Patients presenting with back pain typically report sudden or acute onset of pain in 

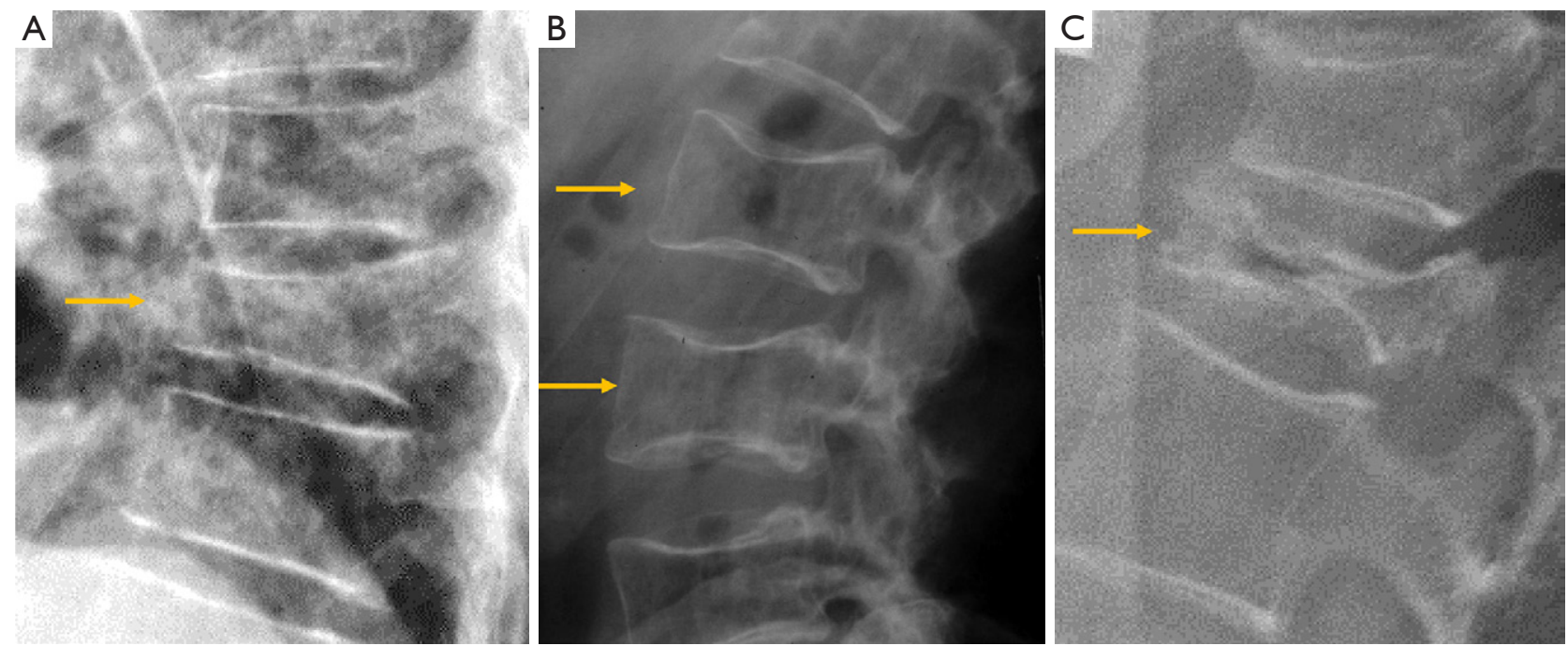

Figure 5 Types of osteoporotic vertebral fractures according to Genant's classification. (A) Wedge; (B) biconcave (with endplates depression); (C) burst fracture. Note the intravertebral vacuum phenomenon in (C). Arrows point the main abnormality in each case.

temporal relationship with relatively atraumatic activities such as bending forward, standing from a seated position, or even with vigorous coughing or sneezing (49). In the absence of localising symptoms, spinal fracture status is usually determined by obtaining lateral radiographs of the spine (50). Low-energy fractures of the spine due to osteoporosis can be detected in radiographs based on their morphologic changes. An alternative method called vertebral fracture assessment (VFA) by DXA (dual-energy X-ray absorptiometry) devices is also available (51). The VFA quality imaging is lower, and the interpretation may be challenging. It is important to identify and report OVF, so that appropriate investigation and treatment can be instigated.

The most frequent site of OVF involvement is the thoracolumbar junction, with the second most frequent region being the midthoracic spine. Vertebral fracture can occur among osteoporotic patients in three possible scenarios: (I) minimal energy trauma which is not noted by patients, (II) low-energy trauma which is defined as forces equivalent to a fall from a standing height or less, and also (III) high-energy trauma. In high-energy trauma the vertebra will fracture even in the absence of osteoporosis, but because the vertebra is osteoporotic, the trauma-induced deformity (i.e., the extent of damage to the vertebra) will be more extensive. Most typical OVFs in epidemiological studies appear as concave deformity, with vertebral middle height loss greater than vertebral anterior height (52-54), which are more associated with minimal traumas unnoticed by the patients. However, in clinical practice OVFs can have various appearances (Figure 5), and at least a portion of OVFs may be like traumatic VFs when a low-energy trauma event is involved. Wang et al. discussed the endplate fracture differences between OVF and traumatic VF. They noted that traumatic VFs rarely have lower endplate fracture without simultaneously having upper endplate fracture (55). Vertebral fractures due to lower energy trauma or highenergy trauma are likely to be seen in their acute or subacute phase in the orthopaedic department or back pain clinics, while OVFs due to minimal energy trauma are more likely to be detected incidentally when undergoing other imaging examinations, or the patients are referred for routine OVF assessment.

Multiple classification systems for OVF have been proposed without general acceptance of a single system to date. The Sugita's classification which considers both deformity and cortex fractures, includes 5 types: swelledfront, bow-shaped, projecting, concave and dented (56) (Figures 6,7). The author observed that the first three types had a poor prognosis, with a higher incidence of late collapse, frequently showing an intravertebral cleft that can be detected in radiographs as an intravertebral vacuum phenomenon. This observation has been supported by the work of Ha et al. (57), who noted that a mid-portion type fracture is a relative risk factor for progressive collapse following the acute fracture event. Sugita $e t$ al. suggested that mid-portion type fractures lead to vascular injury as 


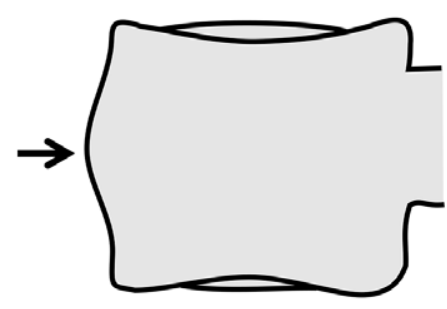

Swelled-front type

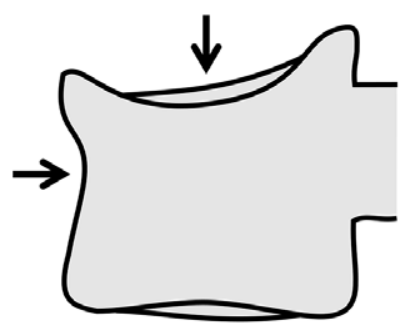

Bow-shaped type

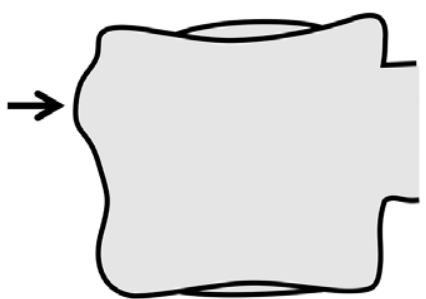

Projecting type

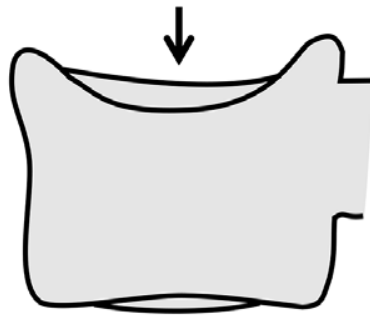

Concave type

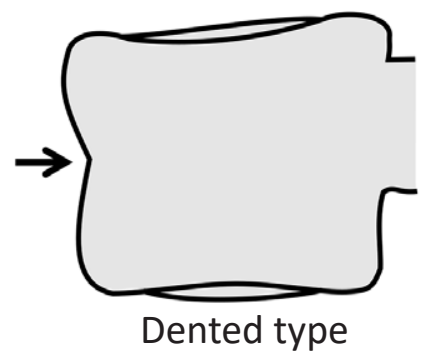

Figure 6 Classification of acute vertebral compression fractures in the elderly according to Sugita et al. Modified from (56).
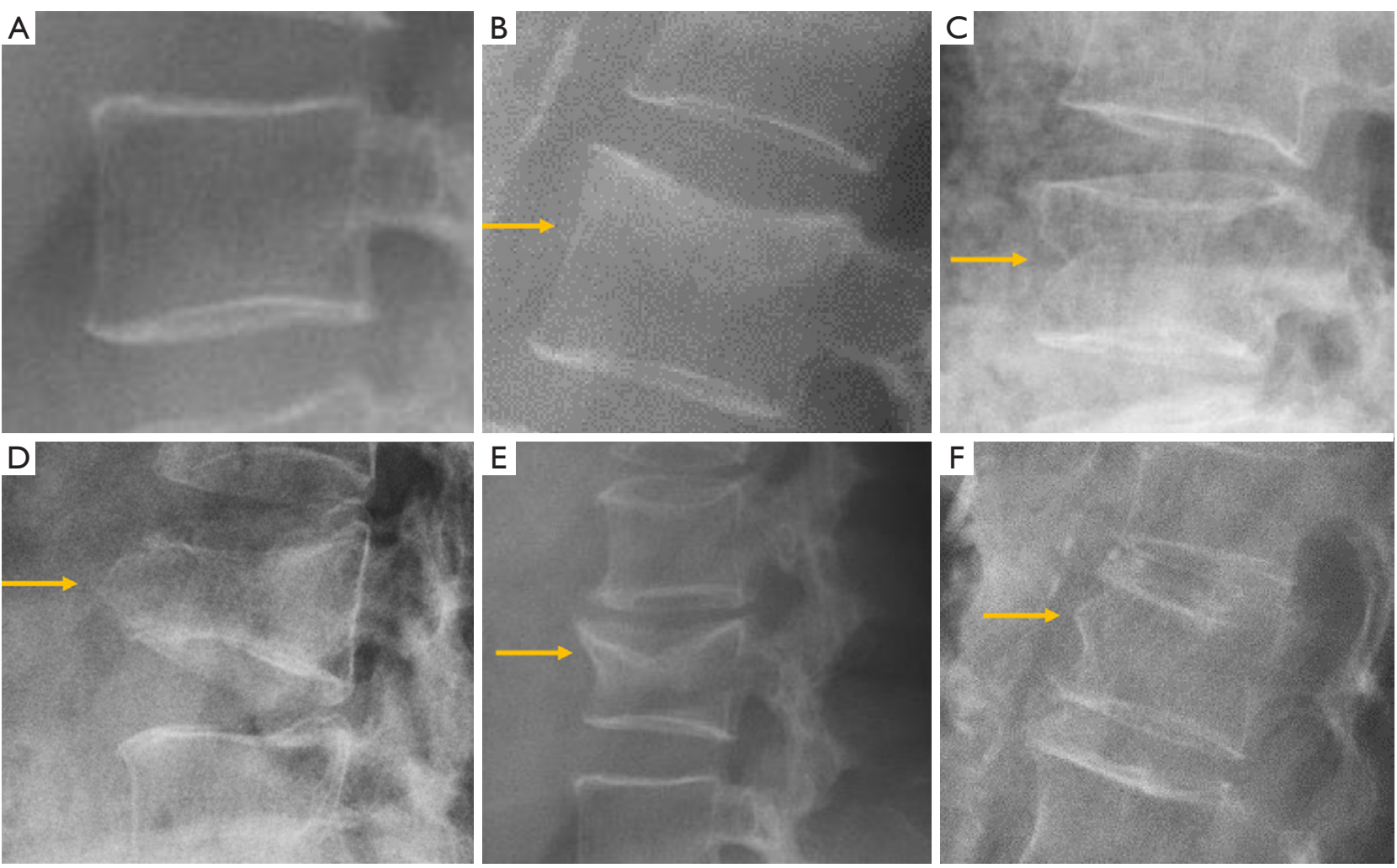

Figure 7 Types of osteoporotic vertebral fractures according to Sugita's classification. (A) Normal; (B) concave; (C) dented; (D) swelledfront; (E) bow-shaped; (F) projecting. Arrows point the main abnormality in each case. 
A

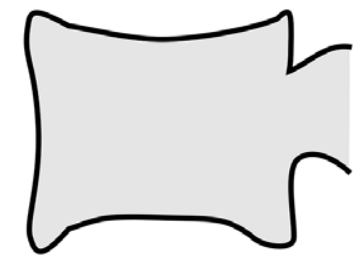

B

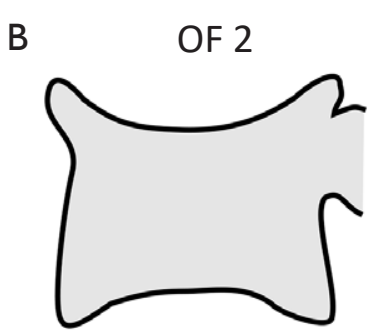

c

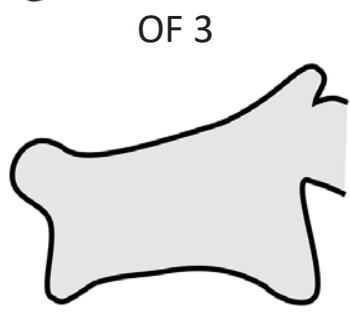

OF 3
D
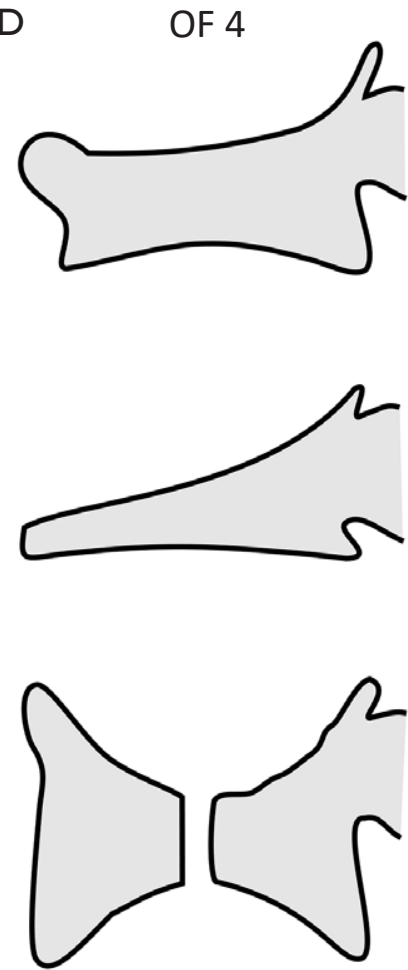

E
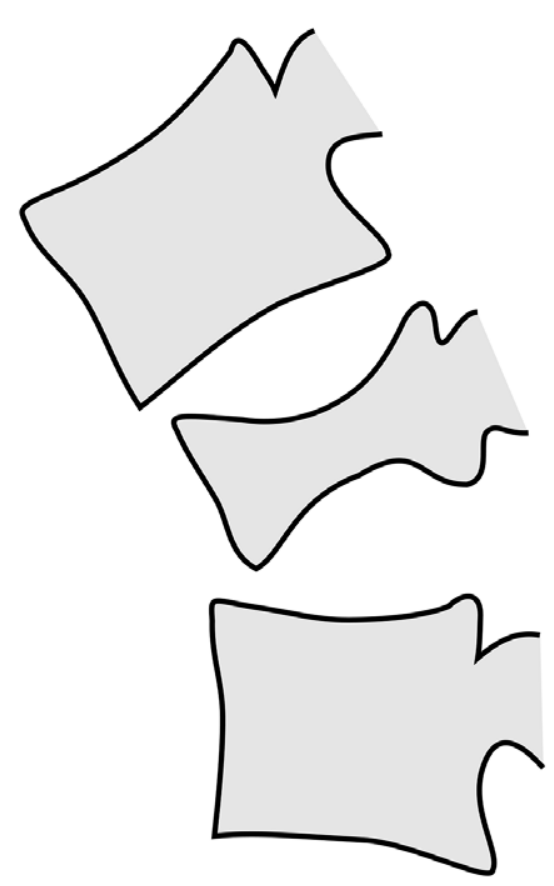

Figure 8 The German Society for Orthopaedics and Trauma (DGOU) Classification of Osteoporotic Thoracolumbar Spine Fractures: (A) Type 1 (OF 1) non deformity; (B) Type 2 (OF 2) deformation with minor involvement of the posterior wall; (C) Type 3 (OF 3 ) deformation with distinct involvement of the posterior wall; (D) 3 examples of Type 4 (OF 4) loss of integrity of vertebral frame architecture or pincertype fracture; (E) Type 5 (OF 5) injuries with distraction or rotation. Modified from (59).

opposed to endplate type fractures (56). These works can be summarised by the rule that acute OVFs with anterior cortex fracture seen in the orthopaedic department are more likely to develop further collapse. In their series, Sugita et al. found that OVFs of swelled-front-type (13.1\%), bow-shaped-type (28.6\%), and projecting-type fractures (16.7\%), all of which were of mid-portion type, counted for $58.3 \%$ of the total VFs, while the concave type counted for $32.1 \%$. They also noted that concave-type fractures mostly occurred without specific trauma, whereas swelledfront-type fractures resulted from apparent accidents. Ha et al. reported that 11 of their $75 \mathrm{VFs}$ were mid-portion type fractures (14.7\%). On the other hand, Lentle et al. (58) reported that only $5 \%$ of their epidemiological study participants had 'anterior cortex buckling'. Recently, the German Society for Orthopaedics and Trauma proposed a classification system for Osteoporotic Vertebral Body Fractures (59) (Figures 8,9). It offers a comprehensive score of the type of fracture and clinical factors to decide between medical or surgical treatment. A score of more than 6 points may result in surgical management (60). This classification includes five types of vertebral fractures. OF (osteoporotic fractures) 1: No vertebral deformation (vertebral body oedema on MR fat-suppressed image only). The stable injury is clearly visible on fat-suppressed image only. $\mathrm{X}$-rays and CT scan do not show vertebral deformation. OF 2: deformation with no or only minor involvement of the posterior wall $(<1 / 5)$. This type of fracture affects one endplate only (impression fracture). The posterior wall can be involved, but only slightly. OF 2 are stable injuries. OF 3: deformation with distinct involvement of the posterior wall $(>1 / 5)$. This type of fracture affects one endplate only, but shows distinct involvement of the anterior and posterior wall (incomplete burst fracture). The fracture can be unstable and may collapse further over time. OF 4: loss of integrity of the vertebral frame structure, or vertebral body collapse, or pincer-type fracture. This subgroup consists of 3 fracture types. In case of loss of integrity of the vertebral 

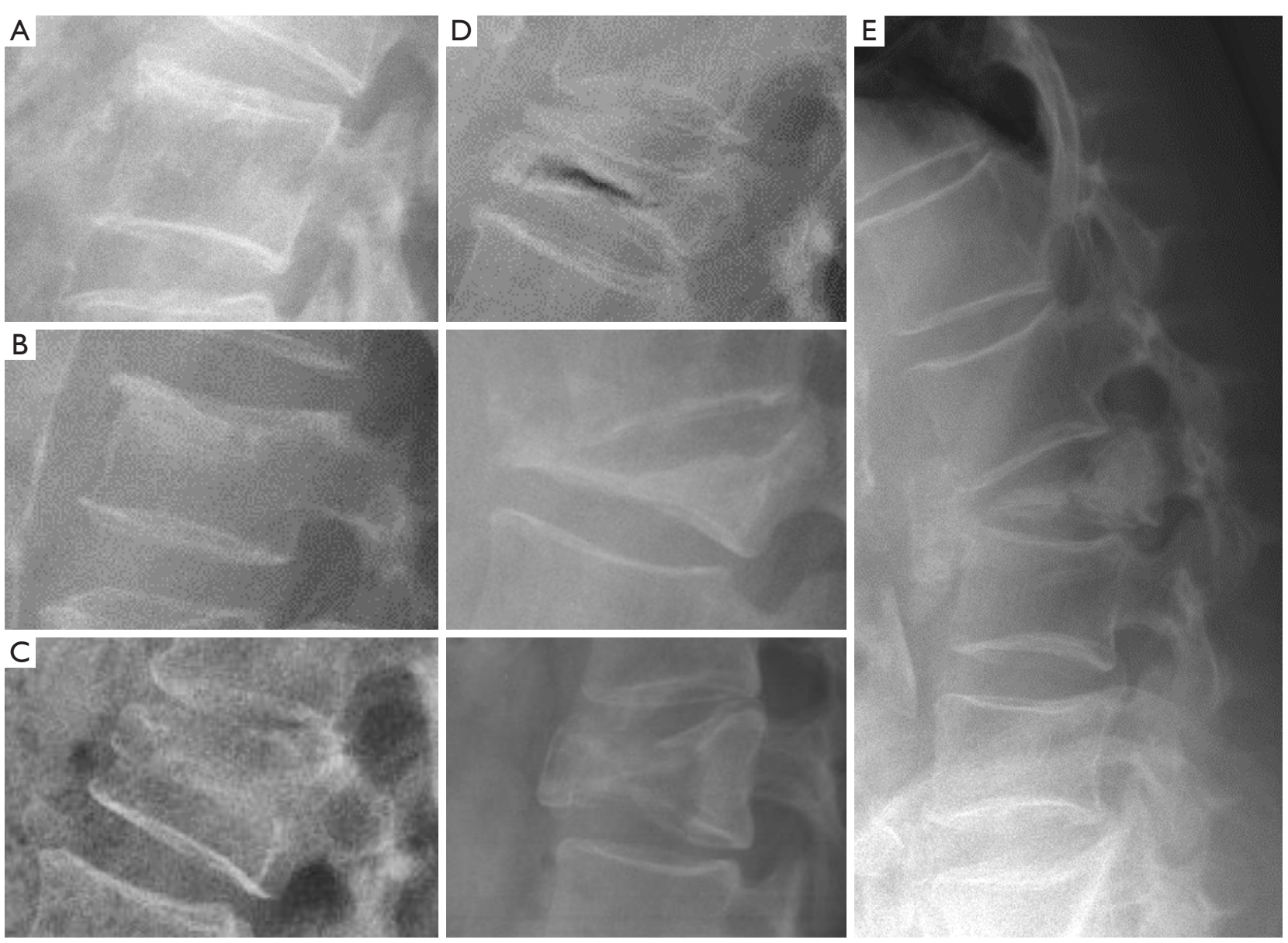

Figure 9 Examples of osteoporotic vertebral fractures according to the German Society for Orthopaedics and Trauma (DGOU) Classification. (A) Type 1-non deformity; (B) Type 2-deformation with minor involvement of the posterior wall; (C) Type 3-deformation with distinct involvement of the posterior wall; (D) 3 examples of Type 4-loss of integrity of vertebral frame architecture or pincer-type fracture; (E) Type 5-injuries with distraction or rotation.

frame structure both endplates and the posterior wall are involved (complete burst fracture). Vertebral body collapse is typically seen as a final consequence of failed conservative treatment and can impose as a plain vertebral body. Pincertype fractures involve both endplates and may lead to severe deformity of the vertebral body. OF 4 injuries are unstable fractures and intravertebral vacuum clefts are often visible. OF 5: injuries with distraction or rotation. This group is rare but shows substantial instability. The injury includes not only the anterior column but also the posterior bony and ligamentous complex. OF 5 injuries can be caused either by a direct trauma or by ongoing sintering and collapsing of an OF 4.

The semi-quantitative (SQ) criteria proposed by Genant's et al. have been commonly used to date for epidemiological studies, with OVFs being classified into three types: wedge, biconcave and crushed fractures $(61,62)$ (Figure 5). Semiquantitative grading of vertebral collapse is based on the percentage of vertebral height loss or vertebral area decrease. According to Genant et al., a vertebral body $(\mathrm{VB})$ is graded on visual inspection of the anterior, middle, or posterior heights as normal (Grade-0), mildly deformed (Grade-1, a 20-25\% reduction in one of the three heights and a reduction in area of 10-20\%), moderately deformed (Grade-2, a 25-40\% reduction in any height and a reduction in area of 20-40\%) and severely deformed (Grade-3, a 40\% or more reduction in height and area). This classification, mainly used in epidemiological studies, has not gained importance in the orthopaedic field. For research purposes, Wáng et al. emphasises the importance of measurement- 


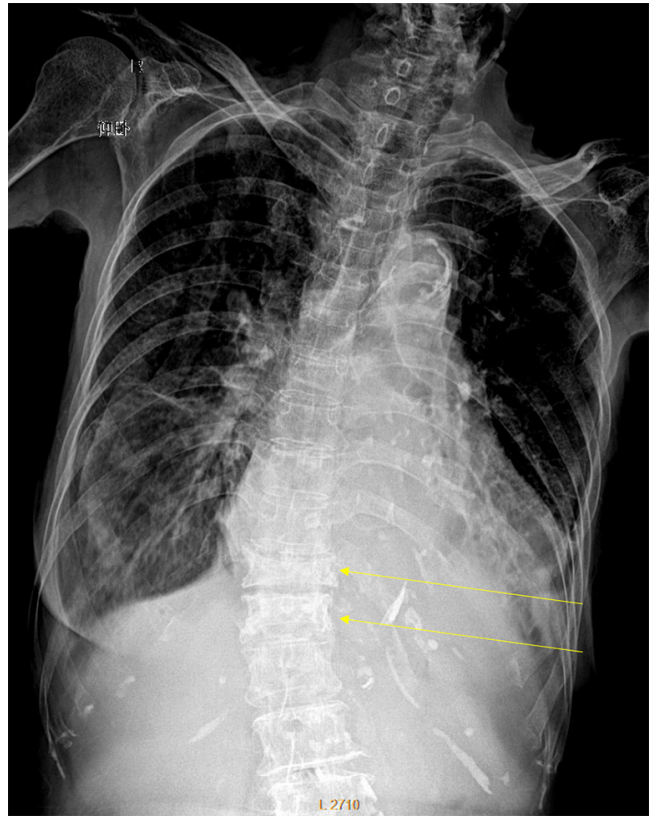

Figure 10 Digital chest radiograph of an 86 years old female. Compressive vertebral deformity of T12 and L1 is noted (arrows).

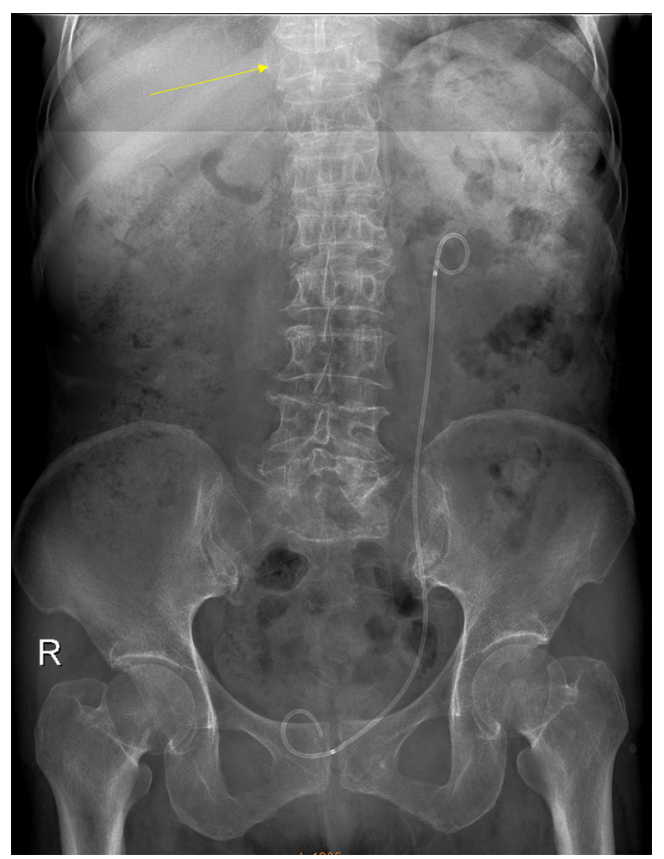

Figure 11 Digital abdominal radiograph of a 71 years old female. Compressive vertebral deformity of T10 is noted (arrow). A left urinary tract drainage catheter can be seen. based grading, rather than visual estimation (63), to improve the comparability of studies by different authors. Recent reports consider that fractures of the vertebral endplate and/or vertebral wall cortex fracture (ECF) have more prognostic implications than isolated vertebral deformities $(58,64)$. Wáng et al. $(65)$ proposed that a VF without ECF should be term "osteoporotic vertebral deformity" (OVD), while those VFs with ECF should be called OVF. According to Lentle et al., OVD is an OVF only when diagnosed based on evidence or findings of endplate, cortical, or trabecular damage (66). To facilitate visual grading of OVD/OVF in women, Wáng et al. proposed to simplify the Genant's SQ classification into three categories: $<1 / 5$ height loss, $1 / 5-1 / 3$ height loss, and $>1 / 3$ height loss. OVD of $>1 / 3$ height loss is always associated with ECF $(65,67)$, and OVF of $>1 / 3$ height loss in elderly women is associated with increased back pain prevalence (Wang YX et al.'s unpublished data).

Despite its importance, many patients with OVF and at high risk for further fracture remain undetected and untreated (68). Particularly, OVFs are often unrecognised on chest radiographs when the radiographs are ordered for non-skeletal conditions $(69,70)$. OVFs are also missed on spine radiograph when not read carefully (71). Based on analysis of digital spine radiograph, Wáng et al. (72) reported that moderate to severe VDs (i.e., with $>25 \%$ vertebral height loss) at middle/lower thoracic and lumbar spine are mostly identifiable on the frontal view, with a small proportion of ambiguous cases that can be clarified by additional lateral view imaging. In clinical practice, frontal chest frontal radiograph is often taken for patients suspected of respiratory diseases, pleural diseases, as well as to assess the heart and large vessels. Abdominal frontal radiograph is taken in patients with abdominal pain, for assessing urinary stone, gastrointestinal gas, etc. It can be envisaged that, depending on the technical condition of the radiograph, a substantial portion of moderate to severe grades of VDs in the mid/lower thoracic spine and lumbar spine are identifiable on a frontal view digital radiograph of the abdomen and chest (Figures 10,11). Thus, opportunity exists for detecting OVFs on digital chest/abdominal frontal radiograph for high-risk osteoporotic patients (such as elderly females $>65$ years) when they are $\mathrm{X}$-rayed for other indications. Radiologists should pay attention to the potential existence of an OVF while reading chest and 

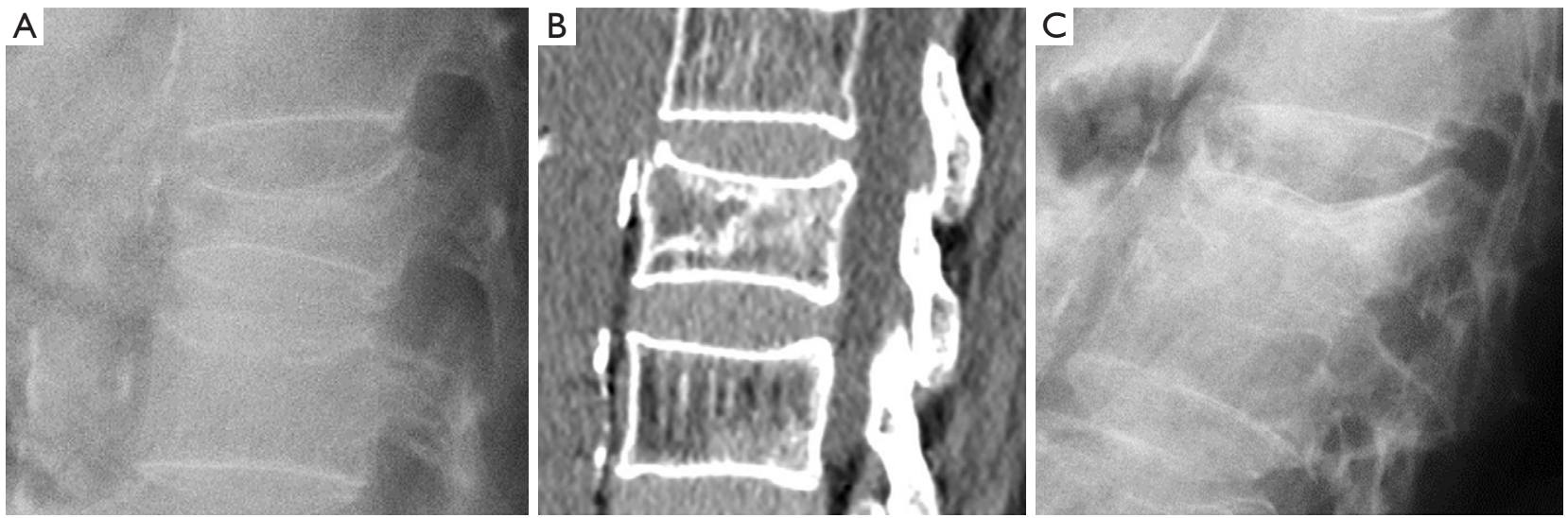

Figure 12 Intravertebral fracture instability. (A) Standing radiograph with marked local kyphosis that is reverted in supine CT (B). (C) Follow-up radiograph showing severe collapse of the vertebral body.

abdominal radiographs of elderly subjects.

Vertebral cleft has been reported in approximately $7-13 \%$ of OVF patients seen in orthopaedic clinics and has been associated with osteonecrosis (Kummel disease), non-union fracture and intravertebral instability $(73,74)$. The presence of intravertebral cleft implies intravertebral instability. Accordingly, several methods have been reported in the literature to assess this instability. It can be quantified as the difference in local kyphosis between flexion and extension radiographs, in standing or prone radiographs (75-77), or comparing the difference in local kyphosis in standing or sitting radiographs with local kyphosis on supine CT (78) (Figure 12).

Of note, most of the studies on OVF epidemiology are based on female patients. The importance of OVF in males remains less certain (38). Wáng et al. reported that for elderly Chinese males (mean age 71.7 years, range 6591 years), existing OVFs were only very weakly associated with higher risk of further development of OVFs during a 4-year follow-up (54).

Finally, it should be noted that the age group with high prevalence of OVF is also the age group with high prevalence of spine metastatic tumours. Differentiating between OVD and metastatic deformity can be sometimes difficult by sole radiograph. MRI is the preferred imaging technique for the differential diagnosis (79).

\section{Degenerative pathology}

Degenerative pathology of the lumbar spine can affect several anatomical locations, including:

(I) Synovial joints: atlantoaxial, facets, costovertebral and sacroiliac.

Facet joints constitute the outer wall of the vertebral foramen. Since they are synovial joints, degenerative signs of osteoarthritis include joint space narrowing, subchondral cysts and/or sclerosis, vacuum phenomenon and osteophyte formation. Due to their posterior location, different projections may be necessary to clearly identify these signs. In lumbar spine, oblique views are more useful with a reported sensitivity of $55 \%$ and specificity of $69 \%$ (80) (Figure 13).

(II) The intervertebral disc, resulting in intervertebral osteochondrosis or scarred disc, and spondylosis deformans or ageing disc.

According to Resnick, osteochondrosis is a process that affects the annulus fibrosus and the nucleus pulposus. It is characterised by narrowing of the intervertebral disc space, central vacuum phenomenon, sclerosis of the vertebral endplates and subchondral bone, and asymmetric osteophytes in any direction (81). From a pathophysiological perspective, osteochondrosis results from radial tears that lead to degeneration of the nucleus pulposus and it is considered a pathologic process associated with vertebral symptoms. Nevertheless, these findings have been described in $19 \%$ of asymptomatic subjects (82) (Figure 13).

Spondylosis deformans predominantly affects the annulus fibrosus. Radiologic signs include symmetrical anterolateral osteophytes, preservation or mild reduction of disc height, peripheral vacuum phenomenon, sclerosis, and/ or amputation of the 

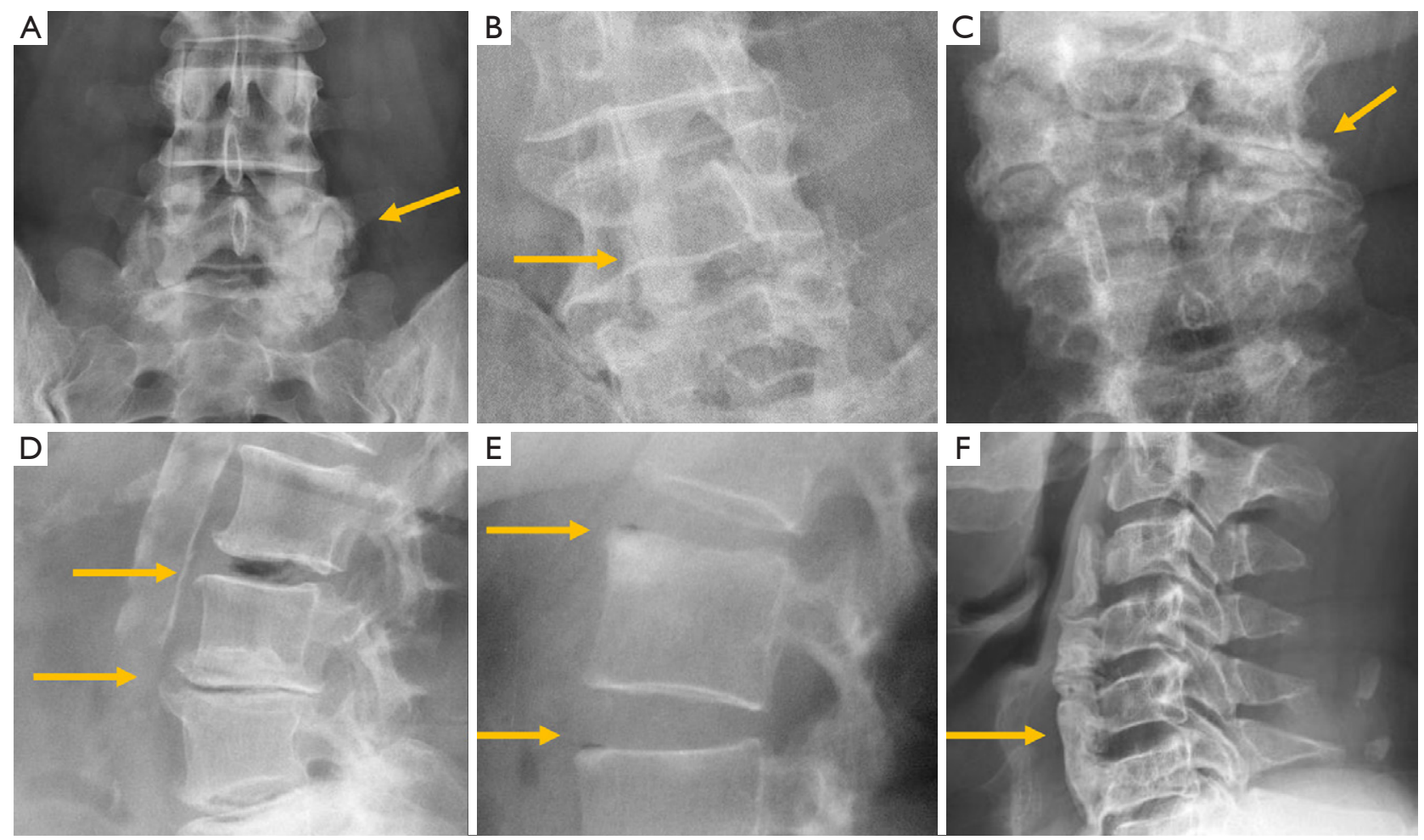

Figure 13 Facet osteoarthritis. AP (A) and oblique (B) lumbar radiographs. (C) Facets osteoarthritis at the cervical spine; (D) vertebral osteochondrosis with marginal osteophytes and central vacuum phenomenon; (E) spondylosis deformans with marginal sclerosis and peripheral vacuum phenomenon; (F) diffuse idiopathic skeletal hyperostosis. Arrows point the main abnormality in each case.

epiphyseal ring. Rim or concentric tears at the annulus fibrosus promote increased instability, while at the insertion of Sharpey fibres, they stimulate osteogenesis, leading to sclerosis and osteophyte formation (83) (Figure 13).

(III) Ligaments and their insertions at the bone, resulting in diffuse idiopathic skeletal hyperostosis (DISH).

DISH is a systemic condition, with an estimated prevalence of approximately $10 \%$ in people $>50$ years of age. The radiographic criterion proposed by Resnik for its diagnosis is the presence of large bridging osteophytes in at least four adjacent thoracic vertebrae. Patients with DISH may be largely asymptomatic. The spinal stiffness in the final stages of the disease implies increased spinal vulnerability to low-energy trauma (84) (Figure 13). On the other hand, the diagnostic criteria proposed by Utsinger greatly reduced the number of spinal bridges required, but involvement of peripheral entheses was included in order to achieve an early diagnosis (85).

(IV) Degenerative changes of the cervical spine typically involve the uncovertebral processes with formation of posterior osteophytes. Associated abnormalities are decreased disc height and disc bulging or protrusion. Plain films are useful for the evaluation of cervical uncovertebral osteoarthritis. In $\mathrm{AP}$ radiograph, the uncinate process becomes blunted and sclerotic, while in lateral radiographs the Mach effect may lead to the false impression of a fracture. The Mach effect is an optical illusion at the margin between areas of different density. In this case presenting as a dark outline of the sclerotic uncinate process (86). The examination should be completed with oblique projections because osteophytes often determine stenosis of the neural foramina and could be missed otherwise (87) (Figure 14).

Degenerative disorders may lead to spinal stenosis, although it may be favoured by the coexistence of developmental spinal stenosis. Radiographs show the 

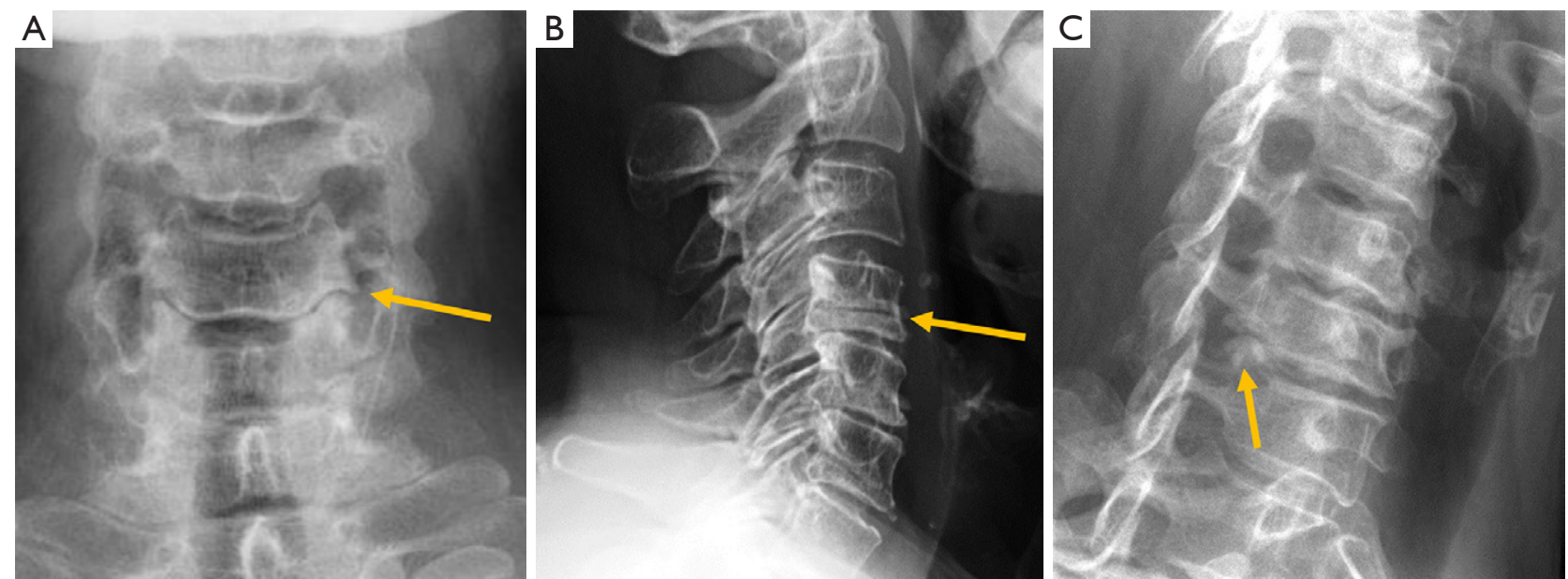

Figure 14 Uncarthrosis. (A) AP radiograph; (B) in the lateral a dark line projected over the vertebral body may simulate a vertebral fracture line; (C) oblique radiograph with osteophytes impinging the vertebral foramen. Arrows point the main abnormality in each case.
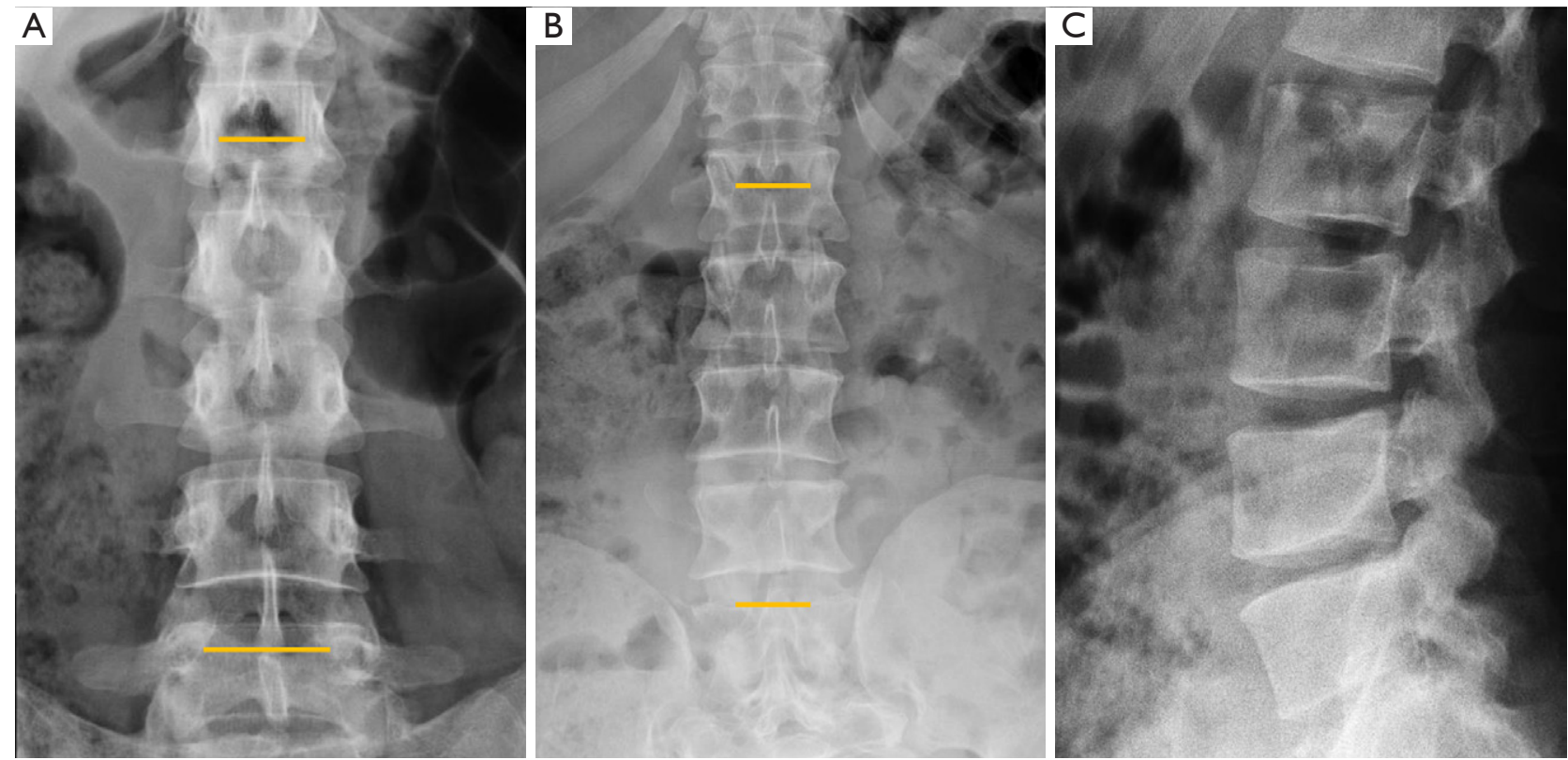

Figure 15 Lumbar spinal canal measurement. (A) Normal AP radiograph showing progressive widening of the interpedicular distance. In congenital stenotic canal; (B) this widening is not present; (C) lateral radiograph of congenital stenotic canal.

bone-related causes of canal stenosis. Congenital stenosis is more frequent in the lumbar tract. It can be part of a skeletal syndrome (e.g., Morquio's disease, achondroplasia, Down syndrome) or be idiopathic. In normal subjects, the interpedicular distance at the lumbar level increases progressively from L1 (range, $17-19 \mathrm{~mm}$ ) to L5 (20-23 mm). This increase is lower or absent in congenital spinal stenosis (87) (Figure 15).
Several indices and measurements have been described in radiographs as diagnostic criteria for developmental stenosis. At the cervical level, a sagittal canal diameter $<14 \mathrm{~mm}$ between $\mathrm{C} 4$ and $\mathrm{C} 7$ or a ratio between the sagittal diameter of the canal and that of the vertebral body $<0.8 \mathrm{~mm}$ are considered signs of central canal stenosis. In the lumbar spine, moderate stenosis is established if the sagittal diameter is between 10 and $14 \mathrm{~mm}$ and severe stenosis if the 

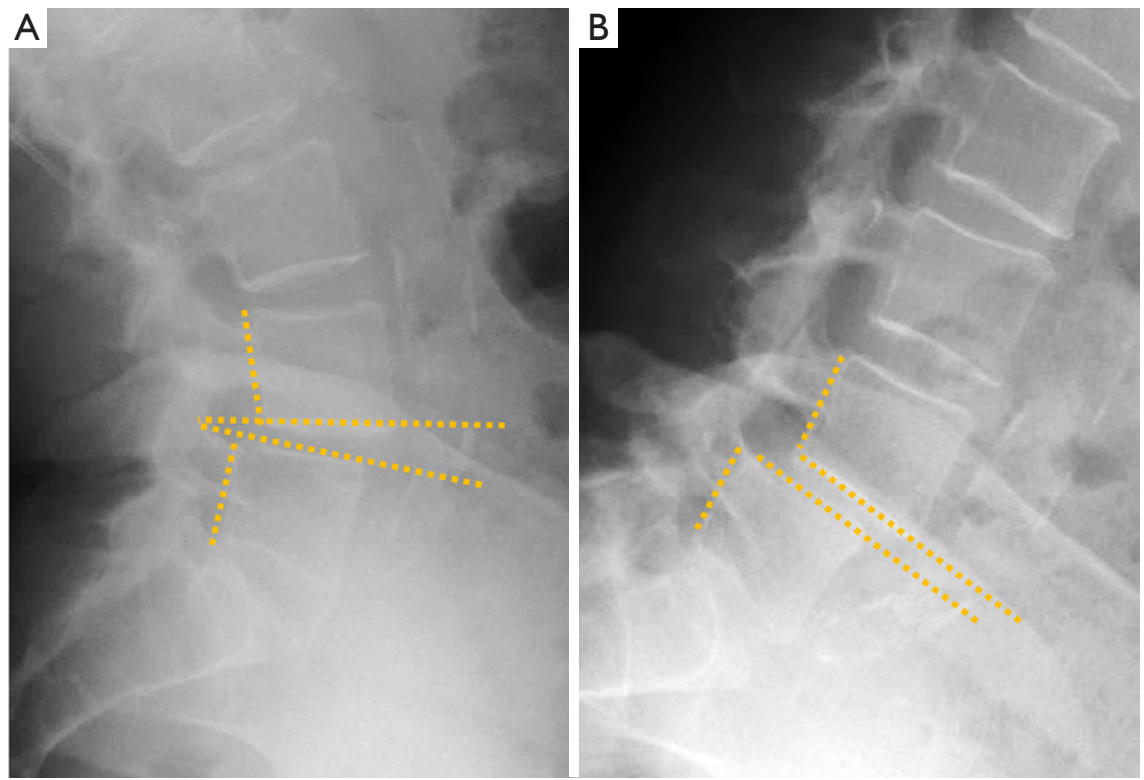

Figure 16 L4-L5 instability. Extension (A) and flexion (B) radiographs demonstrating $5 \mathrm{~mm}$ L4 forward displacement, with subsequent change of the L4-L5 disc angle approximately 20 degrees.

diameter is $<10 \mathrm{~mm}(87)$.

\section{Alignment abnormalities}

Radiographs provide direct information of bone structures. Functional information about misalignment and vertebral stability can be obtained by upright dynamic films in flexion-extension. For the lumbar spine, values of $10^{\circ}$ for sagittal rotation, measured as the shift of the angle between the vertebral endplates of the unstable disc, and more than $3 \mathrm{~mm}$ of sagittal translation are the cut-off conventionally used to diagnose instability (88) (Figure 16). Nevertheless, criteria for the diagnosis of cervical spine instability lack universal agreement, ranging from 1 to $3.5 \mathrm{~mm}$ based on the literature (89), although a 3-mm slippage appears to be a reliable cut-off point (Figure 17). Regarding the atlantoaxial joint, the accepted criteria for instability based on flexionextension radiographs include an interval greater than $3 \mathrm{~mm}$ between the anterior margin of the odontoid process and the posterior cortex of the anterior arch of the atlas (90) (Figure 17).

Six types of spondylolistheses have been described: congenital or dysplastic, isthmic, traumatic, pathologic, iatrogenic, and degenerative (pseudospondylolysis) (87).

According to the classic work of Meyerding (91), vertebral displacement in spondylolisthesis is classified into five grades based on the position of the posterior margin of the upper vertebra over the upper end-plate of the inferior vertebra, which is divided into four equal parts from posterior to anterior. Displacements in each of these quarters of vertebral endplate correspond to grades I to IV, while in grade $\mathrm{V}$ or spondyloptosis, L5 slippage overpasses the anterior margin of S1. Most of the cases seen in a clinical setting are secondary to degenerative or isthmic spondylolisthesis and correspond to grades I and II, whereas grades III and IV are extremely rare (92). Grade V is also rare, and usually secondary to a dysplastic posterior arch, and less frequently to trauma. On AP radiographs, the frontal orientation of the brim of the upper endplate and the transverse processes of L5 can project an image called "the inverted Napoleon hat" sign (Figure 18).

Isthmic spondylolisthesis is the most frequent type of spondylolisthesis in young people and is generally secondary to a stress fracture in a previously normal bone. Spot lateral radiographs allow detecting the bone defect in the pars interarticularis in up to $84 \%$ of the cases (93). However, the $45^{\circ}$ oblique view provides better definition of the isthmic defect, deploying the whole length of the pars interarticularis as the "neck" of a silhouette resembling a "dog" known as the "Scotty dog" in the English literature and as "le petit chien de Lachapelle" in the French literature. Demonstration of spondylolysis in the oblique 

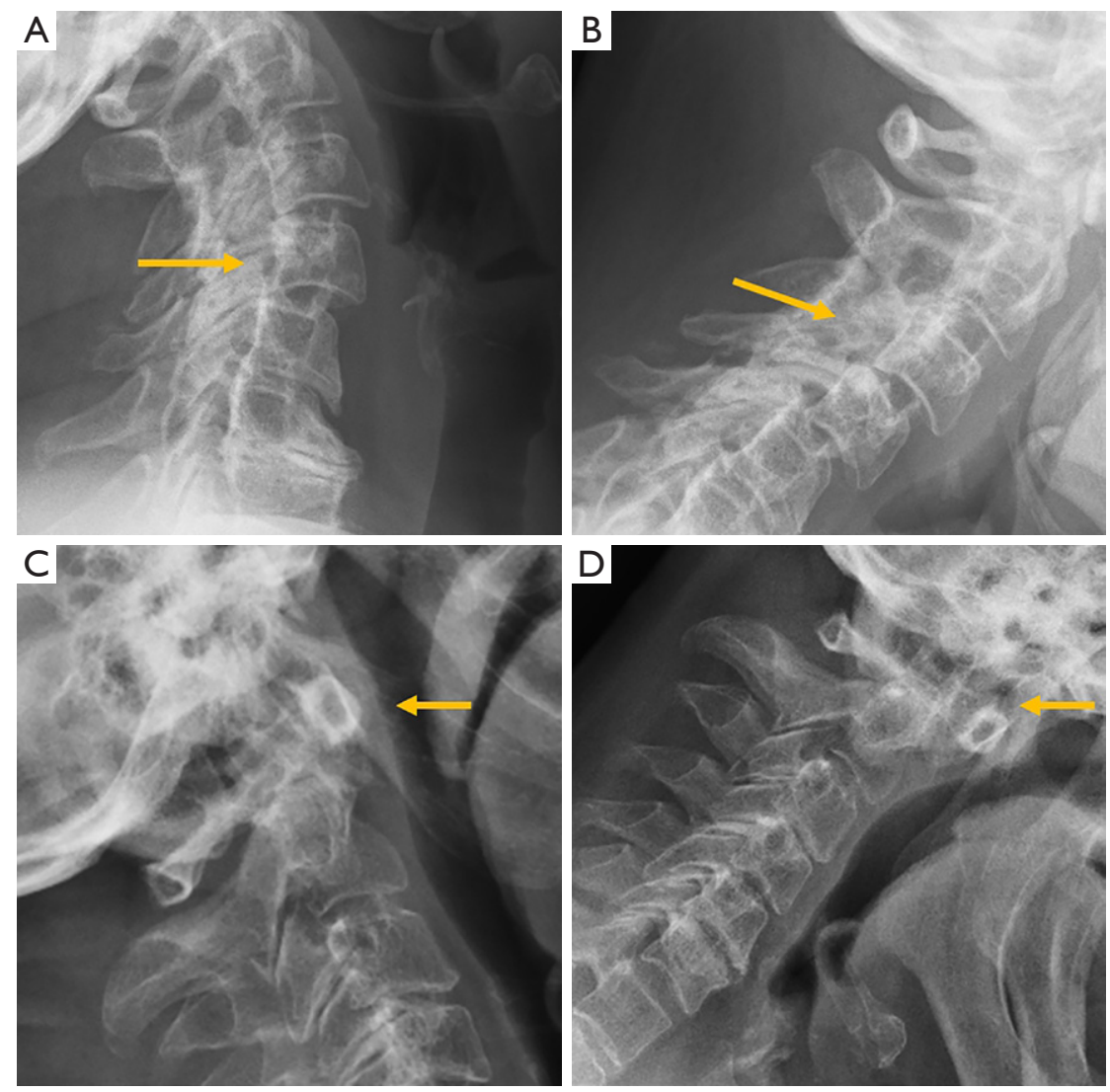

Figure 17 Subaxial cervical instability. Extension (A) and flexion (B) radiographs showing $4 \mathrm{~mm}$ forward displacement of C4. Atlantoaxial joint instability. Extension (C) and flexion (D) radiographs showing $4 \mathrm{~mm}$ forward displacement of the anterior arch of the atlas. Arrows point the main abnormality in each case.

view is depicted as "the collar or broken neck of the Scotty dog" sign. Other authors found that approximately $20 \%$ of defects in the pars interarticularis seen on plain radiographs can only be identified in oblique views (94). Nevertheless, there are secondary signs that help diagnose isthmic spondylolisthesis even if spondylolysis per se is not seen. The spinous process does not shift with the displaced vertebral body and the central canal widens while the foramina are usually stenosed (Figure 18).

The second most common site of neural arch injury following pars interarticularis is the vertebral pedicle. It may be associated with unilateral spondylolysis but has been also described without associated spondylolysis in some young athletes or even in osteoporotic patients (95).

Degenerative spondylolisthesis is secondary to facet and disc degeneration while the neural arch remains intact. For this reason, the spinous process is anteriorly displaced with the vertebral body, and the central canal is usually stenosed
(Figure 17). It is the most frequent cause of spondylolisthesis in elderly subjects (96). It should also be noted that degenerative and isthmic spondylolistheses are not usually clinically relevant, the former being seen in $20 \%$ of the elderly population (97). The prevalence of degenerative spondylolisthesis increases with age, being more common in elderly women than in elderly men, being more common in Caucasian compared to East Asian subjects (98).

Traumatic spondylolisthesis is a rare injury, defined as any acute fracture or dislocation of the posterior elements associated with vertebral spondylolisthesis. When located at $\mathrm{C} 2$, it is called the "Hangman fracture", with radiological signs analogous to isthmic spondylolisthesis (Figure 3).

Retrolisthesis is a manifestation of spondylolisthesis that consist in posterior shifting of a cephalad vertebra over caudal vertebra. It is generally secondary to loss of disc material caused by intervertebral osteochondrosis or acute herniation of the nucleus pulposus (87) (Figure 19). 

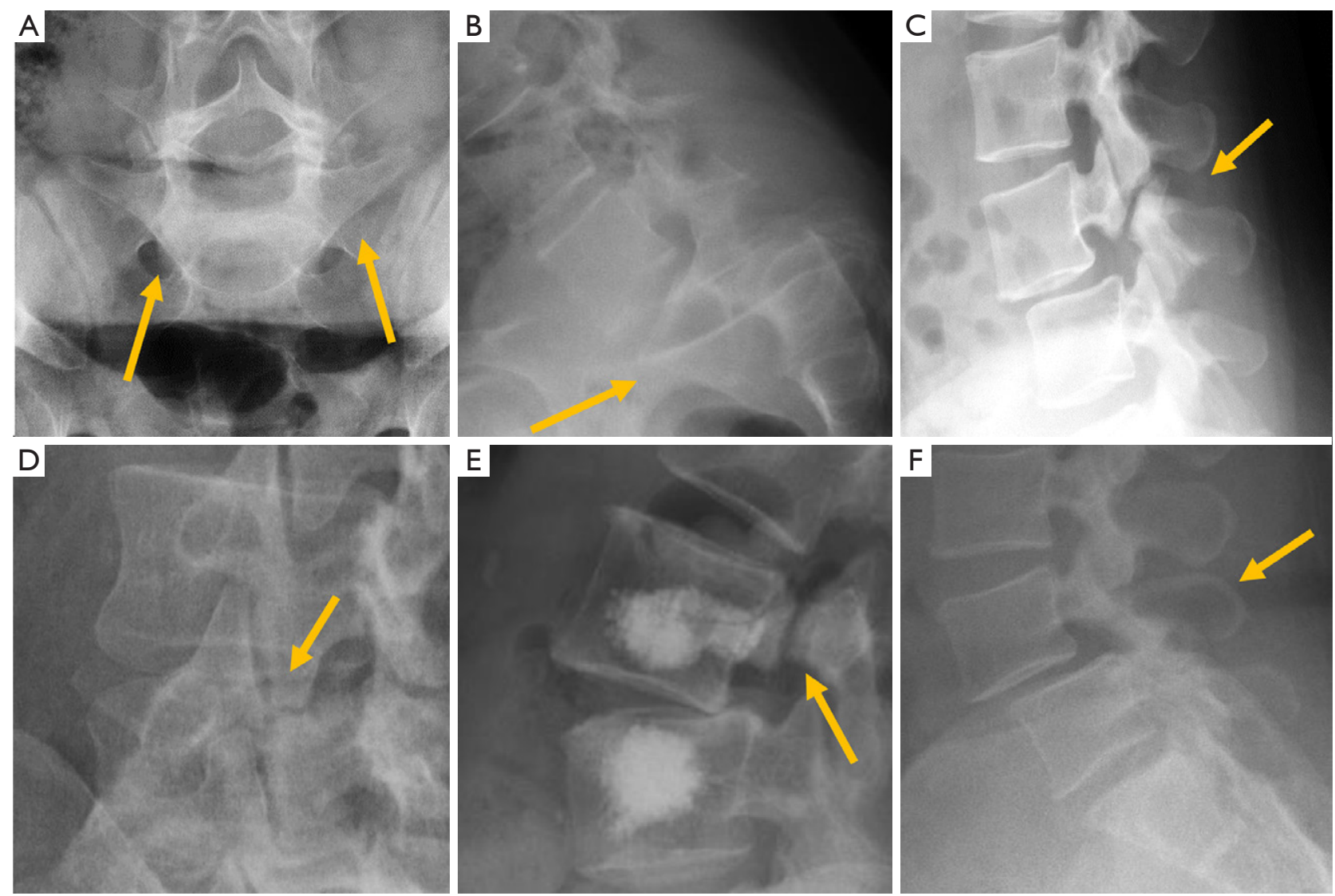

Figure 18 Vertebral spondylolisthesis. (A) Inverted Napoleon hat sign in spondyloptosis (arrows); (B) lateral radiograph in spondyloptosis (arrow points to L5 in front of the sacrum); (C) spondylolysis with spondylolisthesis. The spinous process does not move with the vertebral body; (D) oblique view showing the "broken neck of the Scotty dog" in spondylolysis (arrow); (E) pedicle stress fracture in osteoporotic fracture with previous vertebroplasty; (F) degenerative spondylolisthesis with the spinous process displaced forward (arrow).

\section{Alterations in the spinal curvature}

Vertebral alignment and spinal curvatures can be readily assessed and measured using radiographs that provide a global analysis of the spine.

In the sagittal plane, thoracic kyphosis varies with both age and gender, increasing with age more in women than in men. Reported average normal values in adults range from $20^{\circ}$ to $42.1^{\circ}(99-101)$, with values $<30^{\circ}$ in people in their 20s, and over $50^{\circ}$ in subjects older than 60 years (102). Therefore, there is no uniformly accepted threshold for defining hyperkyphosis or "normal" kyphosis without considering age, sex, and clinical setting (103). The angle is measured between a line parallel to the upper end-plate of the most superior vertebra involved in the kyphotic curve (commonly T4) and another line parallel to the lower endplate of the transitional vertebra between the thoracic and lumbar curves (commonly T12) (101) (Figure 20). Intra- and inter-rater reproducibility of thoracic kyphosis measurement has been demonstrated to be superior for T4-T12 than for T1-T12 or T2-T12 (104), with good agreement $(104,105)$.

During adolescence, juvenile kyphosis-also known as Scheuermann's disease-and idiopathic kyphosis are the two more frequent forms of pathological kyphosis, which is defined by a thoracic kyphotic angle greater than $45^{\circ}$. In Scheuermann's disease, irregular endplates, Schmorl nodes and narrowing of the intervertebral disc can all be found. Vertebral wedging (local kyphosis $>5^{\circ}$ ) must be present in at least one vertebral body, according to Sachs and Bradford's criteria (106), or in three adjacent vertebral bodies, according to Sorensen's criteria (107). When no vertebral abnormalities are present and only anterior wedging of the intervertebral disc exists, the case is classified as idiopathic kyphosis (108) (Figure 21). In physiologic vertebral wedging, 

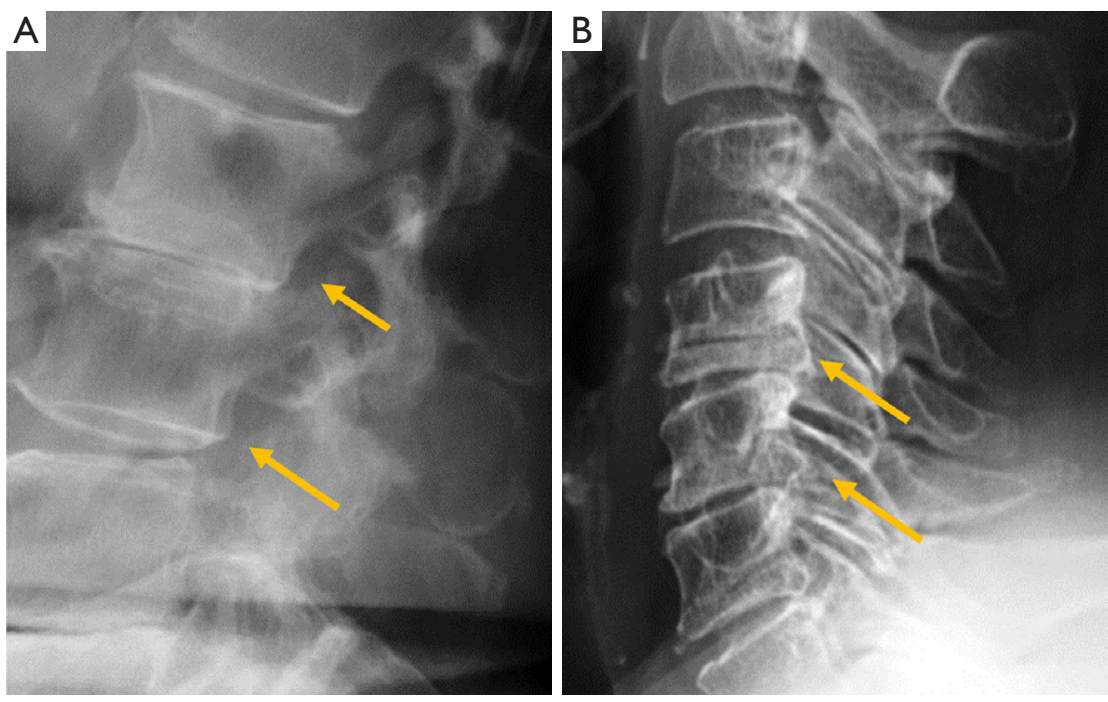

Figure 19 Retrolisthesis (arrow) at lumbar (A) and cervical spine (B).

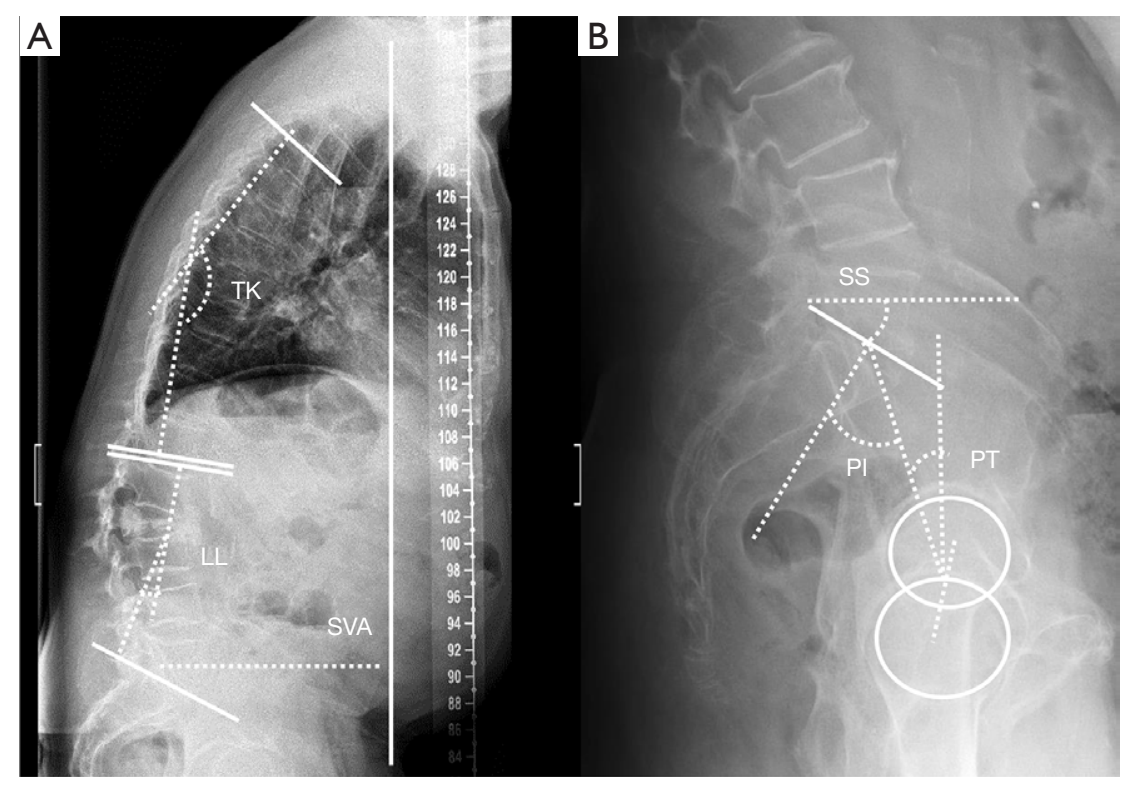

Figure 20 Sagittal alignment of the spine. (A) Measurement of the thoracic kyphosis (TK), lumbar lordosis (LL) and sagittal vertical axis (SVA) showing a positive sagittal balance in a patient with L2 burst fracture; (B) measurement of pelvic incidence (PI), sacral slope (SS), and pelvic tilt (PT).

thoracic kyphosis values are within the normal range and Schmorl's nodes are absent $(109,110)$.

Lumbar lordosis (LL) is measured from the upper endplate of L1 to the upper endplate of S1. Because the normal range of lordosis is very wide $\left(30^{\circ}-80^{\circ}\right.$ using the Cobb method), it is difficult to determine the normal/ optimal lordosis angle for an individual (111). Mean values reported in the literature range from $44^{\circ}-60^{\circ}$ in normal individuals $(112,113)$.

In lateral full-length standing radiographs, sagittal balance is determined by a vertical line (sagittal vertical axis) drawn from the centre of the $\mathrm{C} 7$ vertebral body that should pass over the posterior-superior corner of S1. If the line lies anterior to the posterior-superior corner of S1, the patient 

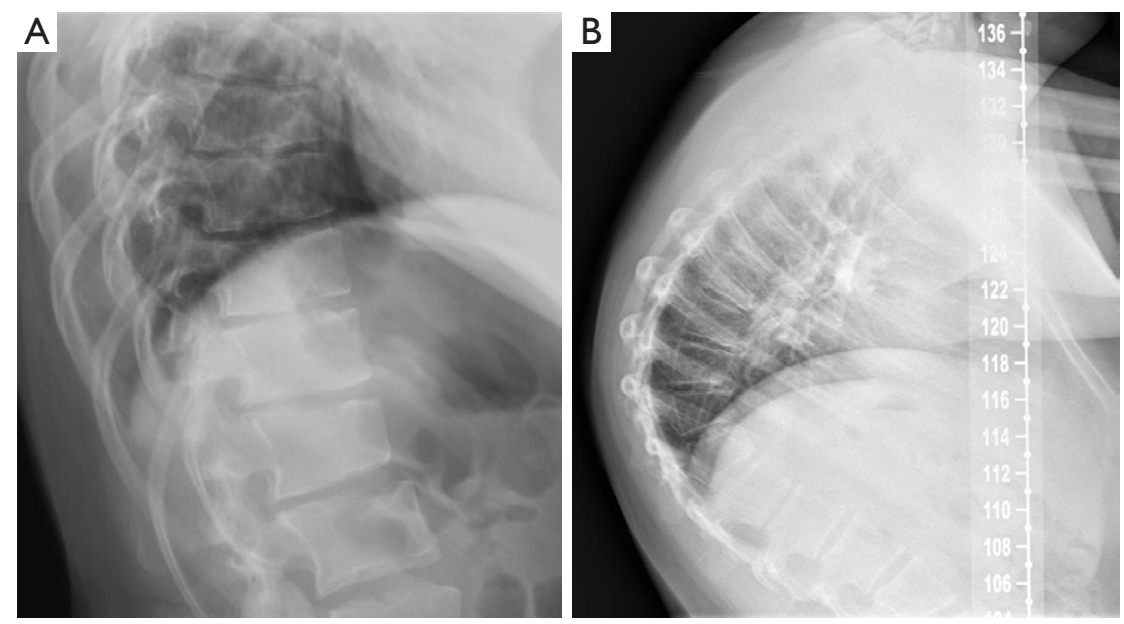

Figure 21 Causes of pathological kyphosis. (A) Typical end-plate changes in Scheuermann's disease; (B) idiopathic juvenile kyphosis.

is said to have a positive sagittal balance (negative sagittal balance in the opposite case). The most common deformity secondary to vertebral fracture is local kyphosis, which may lead to a positive sagittal balance when compensatory mechanisms fail. Physiological spinal ageing or pathologic degenerative loss of disc height may lead to loss of LL and hyperkyphosis, which also disrupts the sagittal balance (114) (Figure 20).

The pelvis is the cornerstone of spinal sagittal alignment. Several measurements have been developed to relate the morphology and position of the pelvis to sagittal spinal alignment. Of these, pelvic incidence (PI) is constant, while sacral slope and pelvic tilt are positional. Therefore, PI is the most suitable parameter for surgical planning, being unique for each patient and showing a strong positive correlation with LL (114,115). A parameter, PI minus (-) LL, quantifies the mismatch between the morphology of the pelvis and the lumbar curve. Values $<10^{\circ}$ are considered the goal of spinopelvic sagittal alignment (116). Nevertheless, compensatory mechanisms must be considered. The decrease in LL is compensated by increased pelvic retroversion and pelvic tilt (117). Ideally, a sagittal vertical axis (SVA)-posterosuperior S1 distance $<40 \mathrm{~mm}$, a PI-LL mismatch within $10^{\circ}$ and a $\mathrm{PT}<20^{\circ}$ have been considered the goals for appropriate sagittal alignment $(114,115)$.

In the coronal plane, scoliosis is defined as a lateral curvature of the spine greater than $10^{\circ}$ when measured on a standing radiograph according to the Cobb method (118). This Cobb angle can be measured manually or digitally $(119,120)$. Idiopathic scoliosis is the most frequent type, although there are rarer cases secondary to congenital vertebral deformities or neuromuscular disorders. In adolescent scoliosis, radiographic findings are used to monitor for curve progression and usually guide the therapeutic options. The AP view should include the iliac crests, which serve to assess skeletal maturation based on the degree of calcification of the iliac crest (Risser method). Lateral bending views are performed to differentiate rigid from flexible curves (Figure 22). In the coronal plane, non-flexibility on side bending $\geq 25^{\circ}$ defines a structural curve (121). In adults, degenerative changes and OVFs lead to deformities that may contribute to scoliosis.

Coronal alignment can also be assessed in AP radiographs, with a vertical line drawn from the middle of the C7 vertebral body that should pass over the centre of the sacrum (122). Coronal imbalance has been defined by some authors when this line deviates $\geq 3 \mathrm{~cm}$ from the centre of the sacrum (123). Based on this line, Qiu categorised degenerative lumbar scoliosis into three types according to the value of global coronal malalignment $(\mathrm{GCM})$ : Type $\mathrm{A}=\mathrm{GCM}<3 \mathrm{~cm}$; Type $\mathrm{B}=\mathrm{GCM}>3 \mathrm{~cm}$ toward the concave side of the main curve; and Type $\mathrm{C}$ $=\mathrm{GCM}>3 \mathrm{~cm}$ toward its convex side (124) (Figure 23). According to some reports, this classification has an influence in postoperative coronal imbalance (124) and functional outcome (125).

\section{Inflammatory pathology}

Despite the improved utility of CT and MRI in spinal inflammatory arthritis, radiography is still recommended 

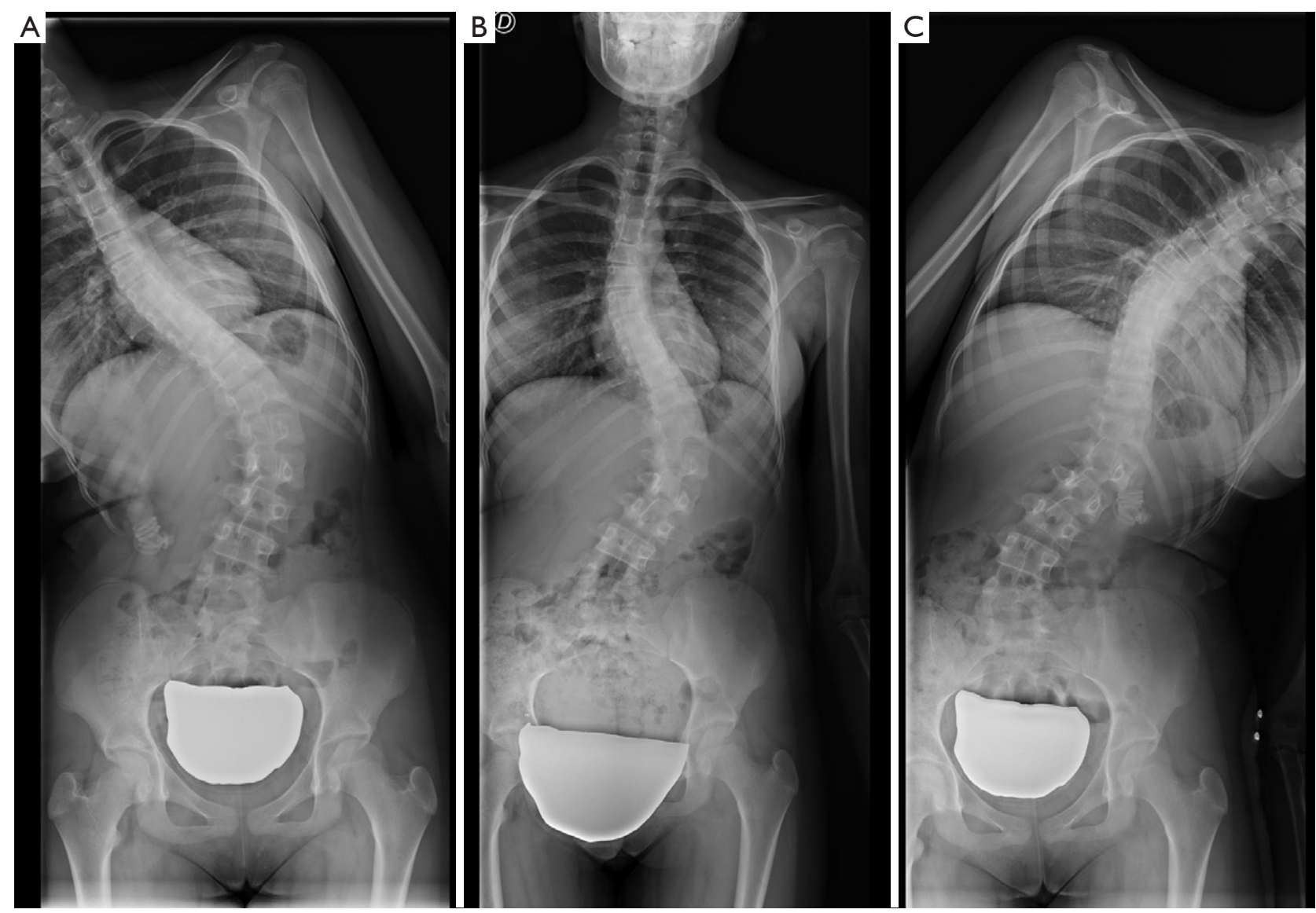

Figure 22 Structural thoracolumbar curve. No significant correction is achieved with bending manoeuvres. (A) Right bending radiograph; (B) AP radiograph; (C) left bending radiograph.

as initial examination to rule out structural damage of the spine (126). According to the modified New York Criteria (NYC), the diagnosis of definite axial spondyloarthropathy (AS) requires the presence of manifest sacroiliitis by radiography (bilateral grade $\geq 2$ or unilateral grade 3-4 sacroiliitis), in addition to clinical criteria (127) (Figure 24). Nevertheless, these criteria do not allow detection of individuals with early disease, in which no structural damage in the sacroiliac joints is seen on radiographs. Currently, the ASAS (Assessment in Spondyloarthritis International Society) classification criteria for AS are the most widely used. Sacroiliitis on imaging is one of these criteria in the imaging arm and includes either the diagnosis of definite radiographic sacroiliitis according to the modified NYC, or active sacroiliitis on MRI $(127,128)$. Some authors differentiate between early non-radiographic AS, when no imaging abnormalities are seen on radiographs with or without inflammatory changes on MRI, and late radiographic AS, when signs of sacroiliitis are present on radiographs according to the NYC $(129,130)$. This is because radiographic changes manifest in the chronic phase, between 3 and 7 years from the onset of the disease (131). Compared to MRI, radiographs show a modest sensitivity (79.8-84.3\%) and specificity (70.6\%/74.7\%) for sacroiliitis and considerable intra-observer variability (132).

Seronegative AS pertain to a group of multisystem inflammatory diseases that includes diagnoses such as ankylosing spondylitis, and lumbar and sacroiliac involvement secondary to inflammatory bowel disease, psoriatic arthritis, and reactive arthritis. Classically, it has been said that ankylosing spondylitis and inflammatory bowel disease tend to show symmetric bilateral involvement, psoriatic and reactive spondyloarthropathy tend to be coarser and more asymmetrical (131-133). However, it has been seen that ankylosing spondylitis 

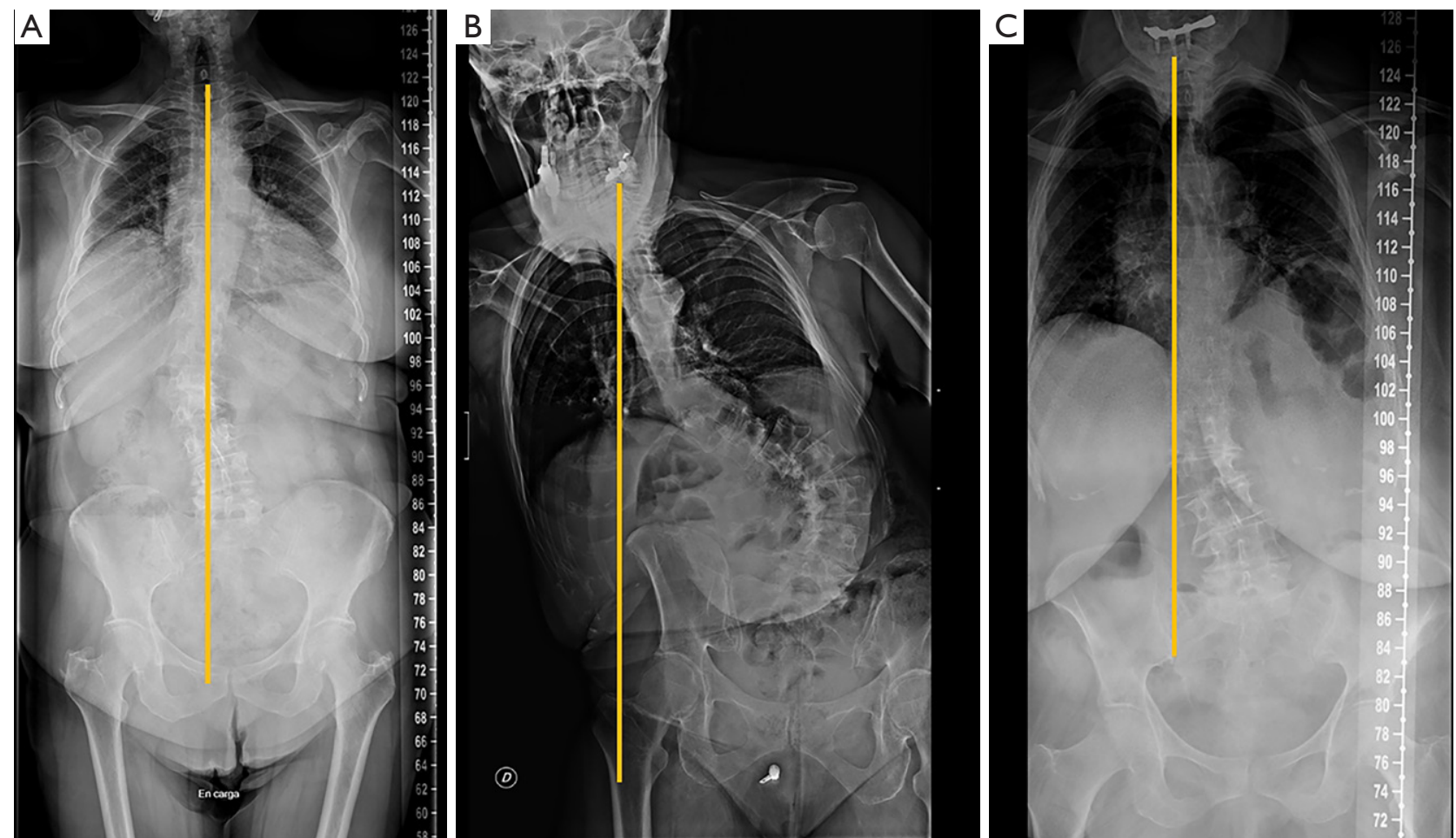

Figure 23 The three types of scoliosis (A,B,C) according to Qiu's classification of global coronal alignment.
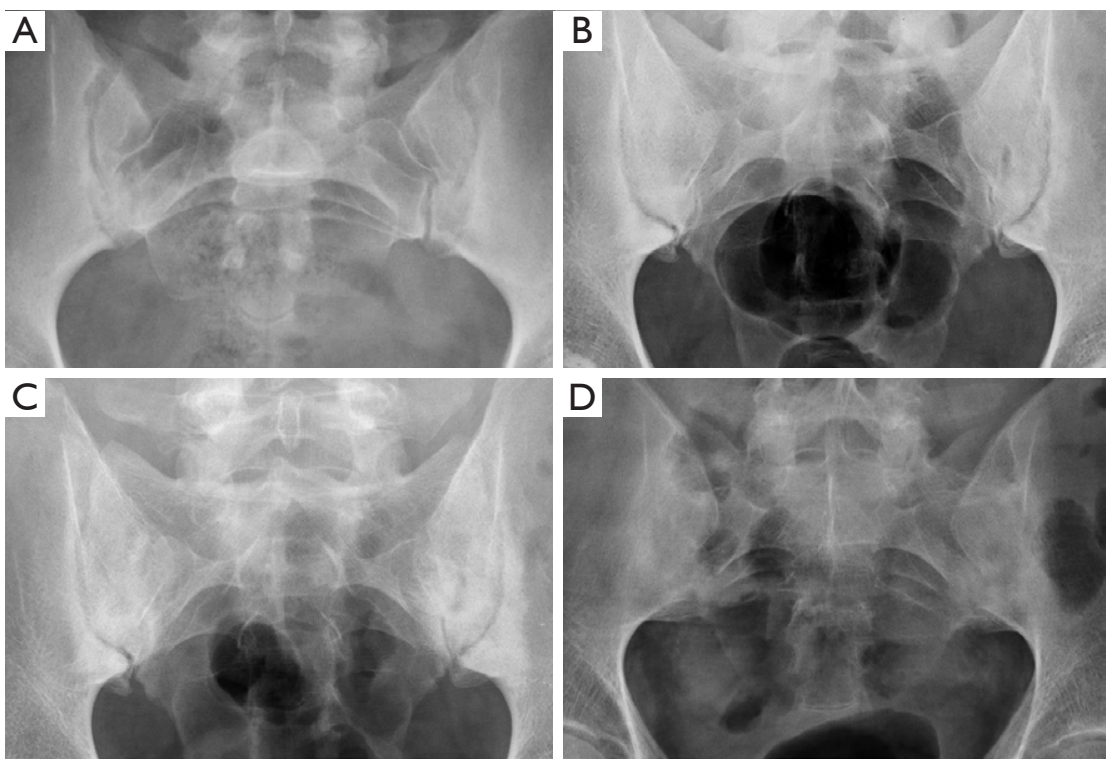

Figure 24 New York sacroiliitis grading. Grade 0 is normal. (A) Grade 1—suspicious changes; (B) Grade 2-minimum abnormality (small localized areas with erosion or sclerosis, without alteration in the joint width); (C) Grade 3-unequivocal abnormality (moderate or advanced sacroiliitis with erosions, evidence of sclerosis, widening, narrowing, or partial ankyloses); (D) Grade 4—severe abnormality (total ankyloses). 

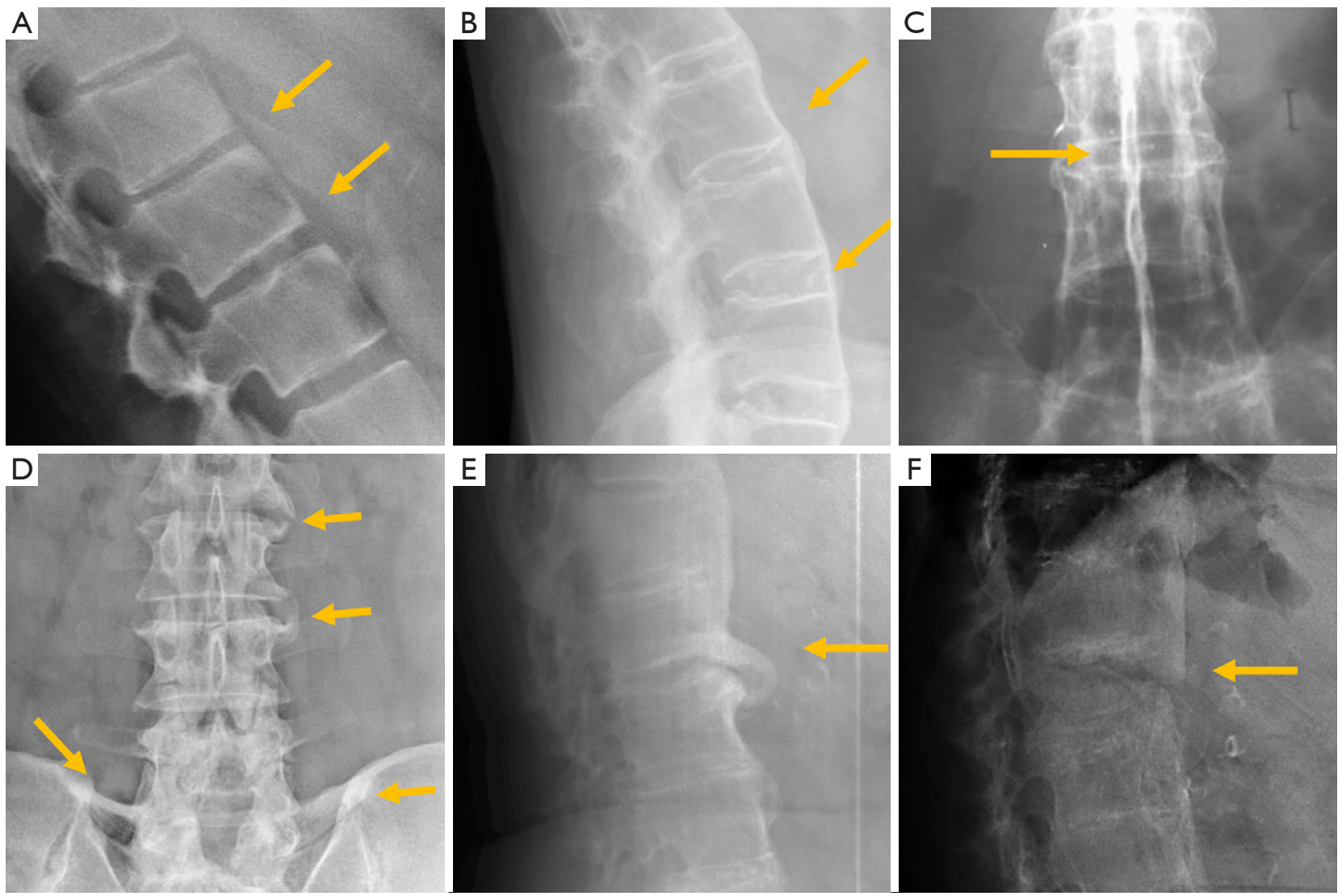

Figure 25 Seronegative spondyloarthropathies. (A) Squaring and shiny corner sign in ankylosing spondylitis; (B) bamboo spine; (C) the dagger sign in ankylosing spondylitis; (D) coarse bone bridges in psoriatic spondyloarthropathy. There is also ossification of the iliolumbar ligaments (lower arrows); (E) bone bridges in psoriatic arthritis before (E) and after bone fractures (F). Arrows point the main abnormality in each case.

can be asymmetrical in the early stages and become symmetrical along the course of the disease $(133,134)$. Changes in psoriatic arthritis can be either symmetrical or asymmetrical, while in reactive arthritis they are symmetrical in about $50 \%$ of the cases (135).

Ankylosing spondylitis is the most frequent form of spondyloarthropathy and shows relatively typical radiographic features at the spine. Characteristic early radiographic changes consist of vertebral squaring and sclerosis of vertebral corners (shiny corners or Romanus lesion). Erosive changes within intervertebral spaces (Andersson lesions) have been detected by radiography in approximately $5 \%$ of patients with this condition (136). If the disease progresses, slim ossifications between vertebral bodies (syndesmophytes) bridge the vertebral bodies, fusing the discs and the facet joints. Associated arthritis/ankylosis due to ligamentous ossification also contributes to spinal stiffness leading to a complete spinal fusion called "bamboo spine". A hyperdense line along the central spine secondary to ossification of interspinous and supraspinous ligaments on frontal radiographs is known as the "dagger sign" (126) (Figure 25). Fractures of the vertebrae at the ligamentous bridges have been reported to occur in up to $6 \%$ of patients with ankylosing spondylitis, especially in patients with long disease duration (137). Psoriatic patients also have an increased risk of vertebral fractures (138). Radiologic findings of spondyloarthropathy secondary to inflammatory bowel disease can be indistinguishable from those of ankylosing spondylitis. Nevertheless, in psoriatic and reactive spondyloarthropathy, bone bridges tend to be coarser and more prominent (126).

In rheumatoid arthritis the focus is the cervical spine, where the atlantoaxial joint may be affected by the inflammatory pannus, leading to structural changes and alignment abnormalities with displacement of the atlas in 

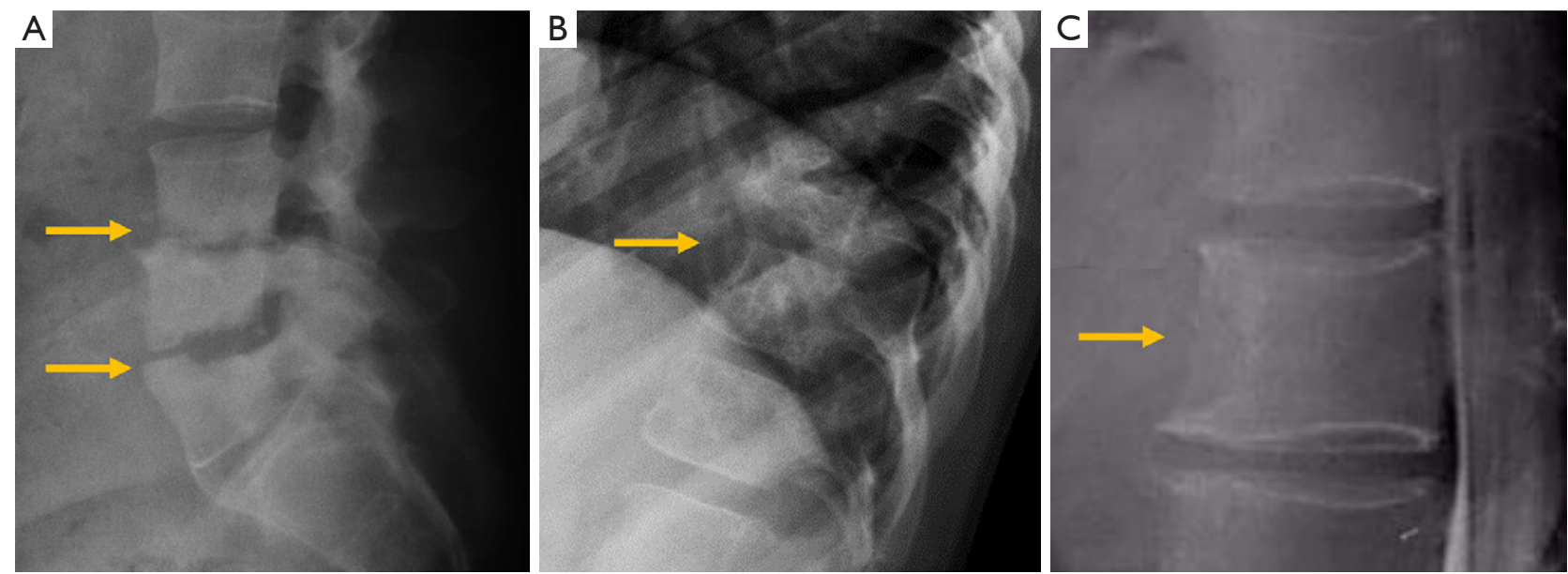

Figure 26 Infectious pathology of the spine. (A) Pyogenic spondylodiscitis in L4-L5 and L5-S1; (B,C) subligamentous spread of the infection in two cases of tuberculous spondylodiscitis. Arrows point the main abnormality in each case.

anterior, posterior, lateral or vertical direction (Figure 17). Younes et al. recommend cervical spine radiography in all patients with RA lasting $>2$ years because cervical involvement occurs in over $70 \%$ of these patients and up to $17 \%$ are asymptomatic (139).

\section{Infectious pathology}

For suspected spinal infection, MRI is the preferred imaging technique due to its high sensitivity and specificity. Nevertheless, radiographs may be appropriate in some scenarios, depicting structural changes, such as bone destruction and secondary alignment abnormalities (3).

Spondylodiscitis accounts for 2-4\% of all osteomyelitis. Radiographic findings include destruction of two adjacent vertebral endplates with narrowing or disappearance of the disc space which, in turn, can cause an acquired vertebral block (140). In pyogenic spondylodiscitis, the first signs on radiographs may take 2-8 weeks to develop (141).

The evolution of pyogenic infections is much faster compared with tuberculosis due to the release of proteolytic enzymes in the former group. Tuberculosis usually exhibits a more chronic pattern, and radiographic changes take longer to become apparent, between 8-12 weeks (142). Subligamentous spread of tuberculosis can occur before spreading to the intervertebral space. In this case, erosion or scalloping of the anterior vertebral wall can be detected on radiographs (143) (Figure 26).

\section{Tumour pathology}

Tumour of the spine may be metastatic, primary benign or primary malignant. Because of overlapping of osseous structures of the spine, conventional radiography is often insufficient and further characterisation with CT or MRI is needed (144).

Metastatic lesions can manifest on radiographs with an osteolytic, osteoblastic, or mixed pattern. Plainfilm radiography is somewhat insensitive regarding the visualisation of bone destruction or marrow replacement. Based on the size of the lesion, between $30-50 \%$ of bone destruction is needed before the lesions become visible on radiographs $(145,146)$.

Destruction of the pedicle typically indicates that the lesion is advanced since it rarely occurs in a primary or isolated form (147). Unilateral destruction of the pedicle is usually responsible for the "winking owl" or "one-eyed vertebra" sign. Occasionally, destruction of both pedicles may lead to the "blind vertebra sign" in which there is no rounded shape of any of the pedicles in the AP view (148). Lung, thyroid and kidney metastases are fundamentally osteolytic lesions (Figure 27). Other osteolytic metastases can be secondary to bladder, nasopharyngeal carcinoma, and colon and, in childhood, to neuroblastoma (Figure 27) $(144,149,150)$.

The detection of osteoblastic lesions may also be delayed with conventional radiographs. One study reported that in 

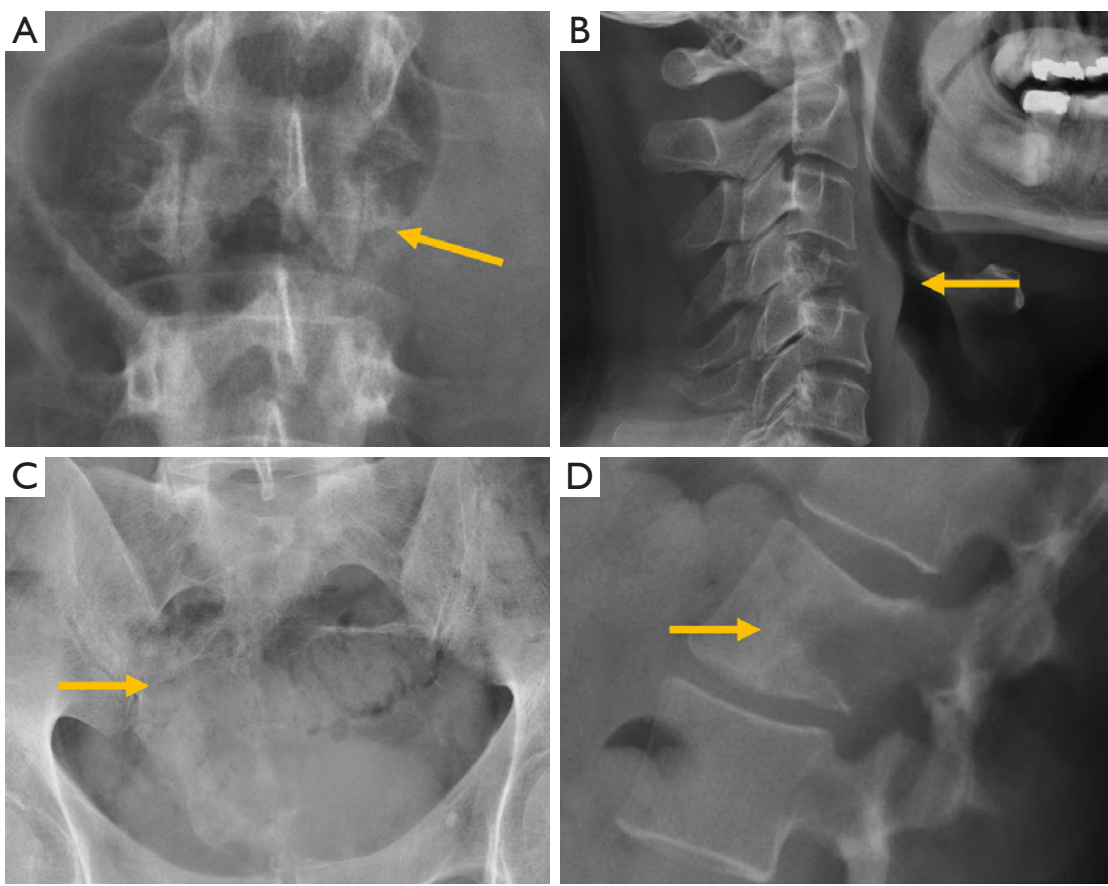

Figure 27 Osteolytic metastases. (A) "One-eyed vertebra" sign in metastasis of bladder carcinoma; (B) thyroid metastasis in C4; (C) sacral osteolysis in metastasis of kidney tumour; (D) osteolytic metastasis in lung cancer. Arrows point the main abnormality in each case.

the case of breast cancer, radiography detection of these lesions may be delayed up to 3-6 months (151). Most commonly, metastases from breast and prostate cancer present with a sclerotic pattern (Figure 28). In adults, other sources of osteoblastic metastases are lymphoma, carcinoid tumours, mucinous adenocarcinoma of the gastrointestinal tract, pancreatic adenocarcinoma, bladder carcinoma or nasopharyngeal carcinoma; in childhood, neuroblastoma and medulloblastoma are the main primary source $(144,149,150)$ (Figure 28).

Primary benign tumours may also show osteolytic, osteoblastic or mixed patterns. Osteolytic benign tumours or pseudo tumours include osteoid osteoma, osteoblastoma, haemangioma, giant cell tumour, aneurismal bone cysts or eosinophilic granuloma. Haemangiomas are one of the most frequent benign tumour lesions seen in the spine. On radiographs, they can be observed when enough destruction of the spongy bone marrow occurs. The remaining trabeculae thicken, revealing a classic "corduroy cloth" pattern within the osteolytic area (152). Extreme collapse of the vertebral body, vertebra plana or coin-on-edge vertebra is a typical feature of eosinophilic granuloma, a benign tumour-like disorder characterised by clonal proliferation of Langerhans cells (Figure 29).
Benign sclerotic tumours or pseudotumours include bone island (enostosis), sclerosis secondary to osteoid osteoma, or healed benign lesions such as cysts or fibromas. Bone island, or enostoma, is often considered a variant of normality. It appears when compact bone develops within the bone marrow. Sometimes, it may be difficult to differentiate enostomas from malignant osteoblastic lesions $(144,152)$ (Figure 30).

Osteochondroma is a benign developmental exophytic lesion rather than an actual tumour. Spinal osteochondromas account for $1-4 \%$ and $9 \%$ of all solitary and multiple osteochondromas, respectively. Radiographically, osteochondroma is a bone exostosis protruding from the bone and showing varying degrees of chondroid calcification of the cartilaginous cap (153) (Figure 30).

Regarding primary malignant tumours, chordoma, plasmacytoma, osteosarcoma and primary lymphoma of the bone are rare, while myeloma is the most common. Chordomas usually present with an osteolytic pattern and soft tissue mass. They usually appear in the sacrococcygeal region ( $50 \%$ of cases), followed by the sphenooccipital region (35\%) and the vertebral bodies (15\%). Osteosarcoma often presents with osteoid calcification of 

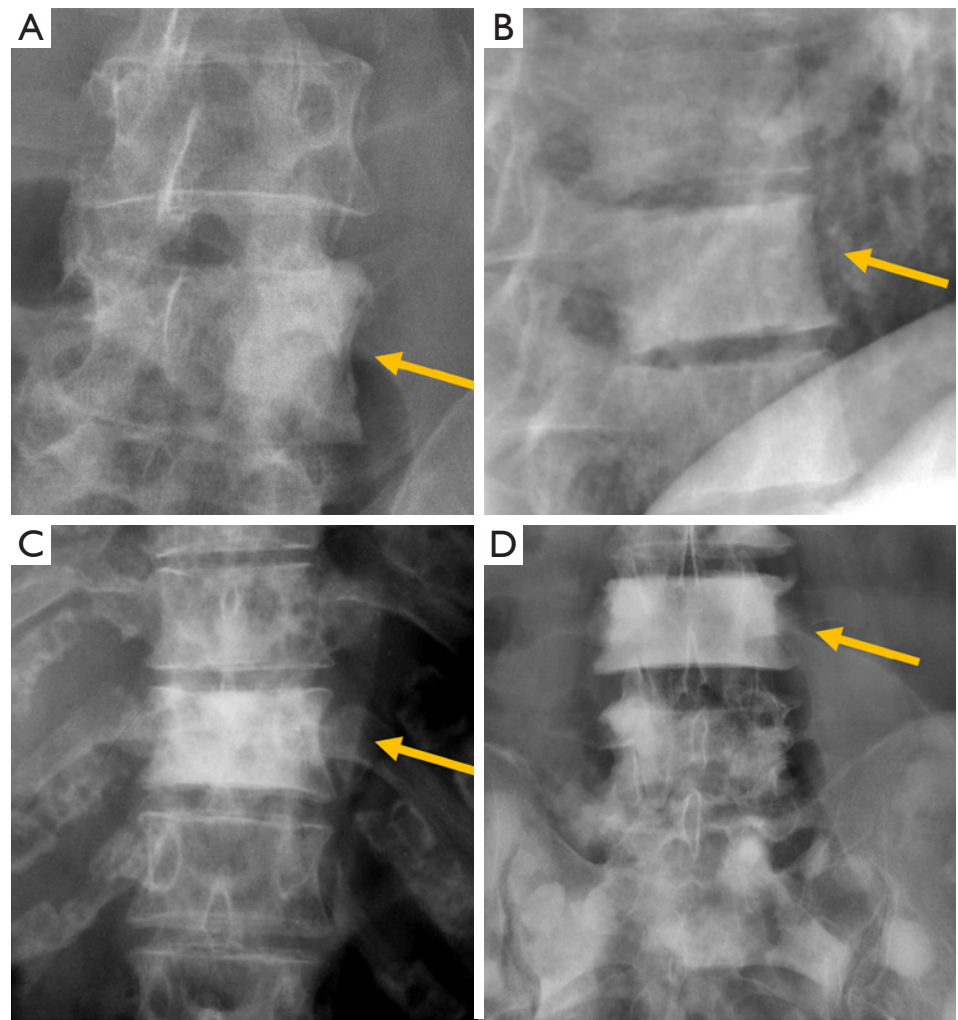

Figure 28 Sclerotic metastases in urothelial tumour (A), nasopharyngeal carcinoma (B), breast cancer (C), and prostate carcinoma (D). Arrows point the main abnormality in each case.
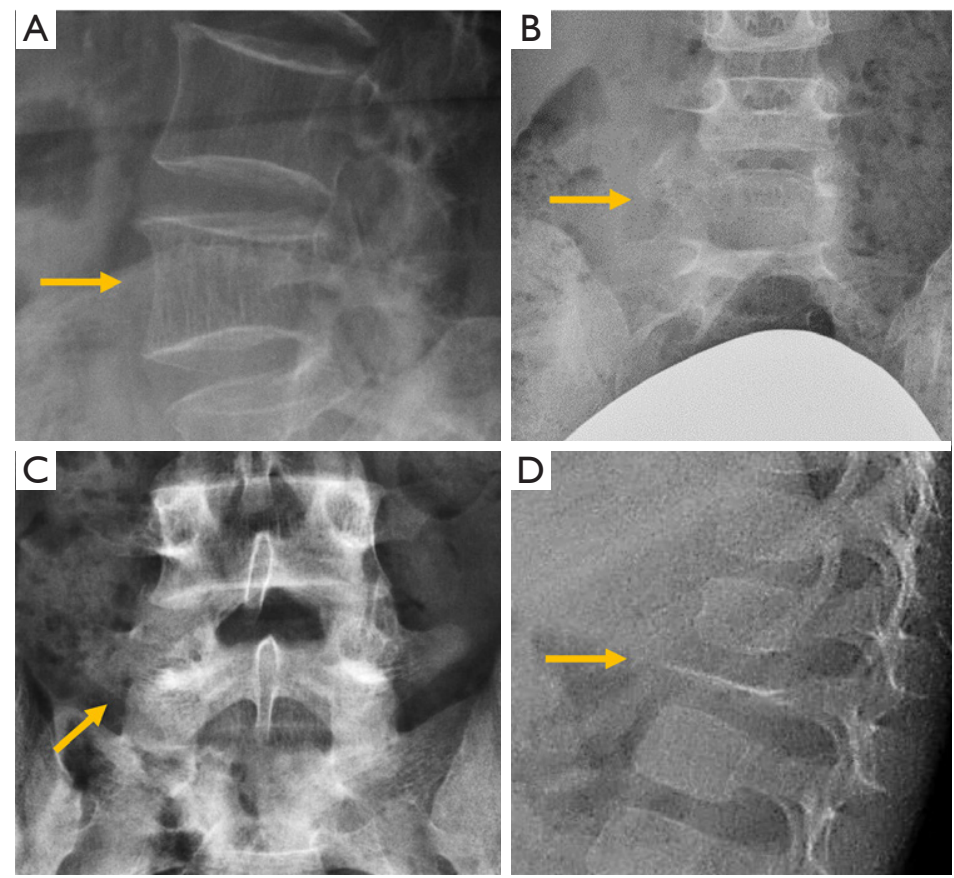

Figure 29 Benign osteolytic tumours and pseudotumours of the spine. (A) "Corduroy cloth" pattern in vertebral haemangioma. (B) "Oneeyed vertebra” sign in aneurysmal bone cyst (B) and in osteoblastoma (C). (D) Vertebra plana in eosinophilic granuloma. Arrows point the main abnormality in each case. 

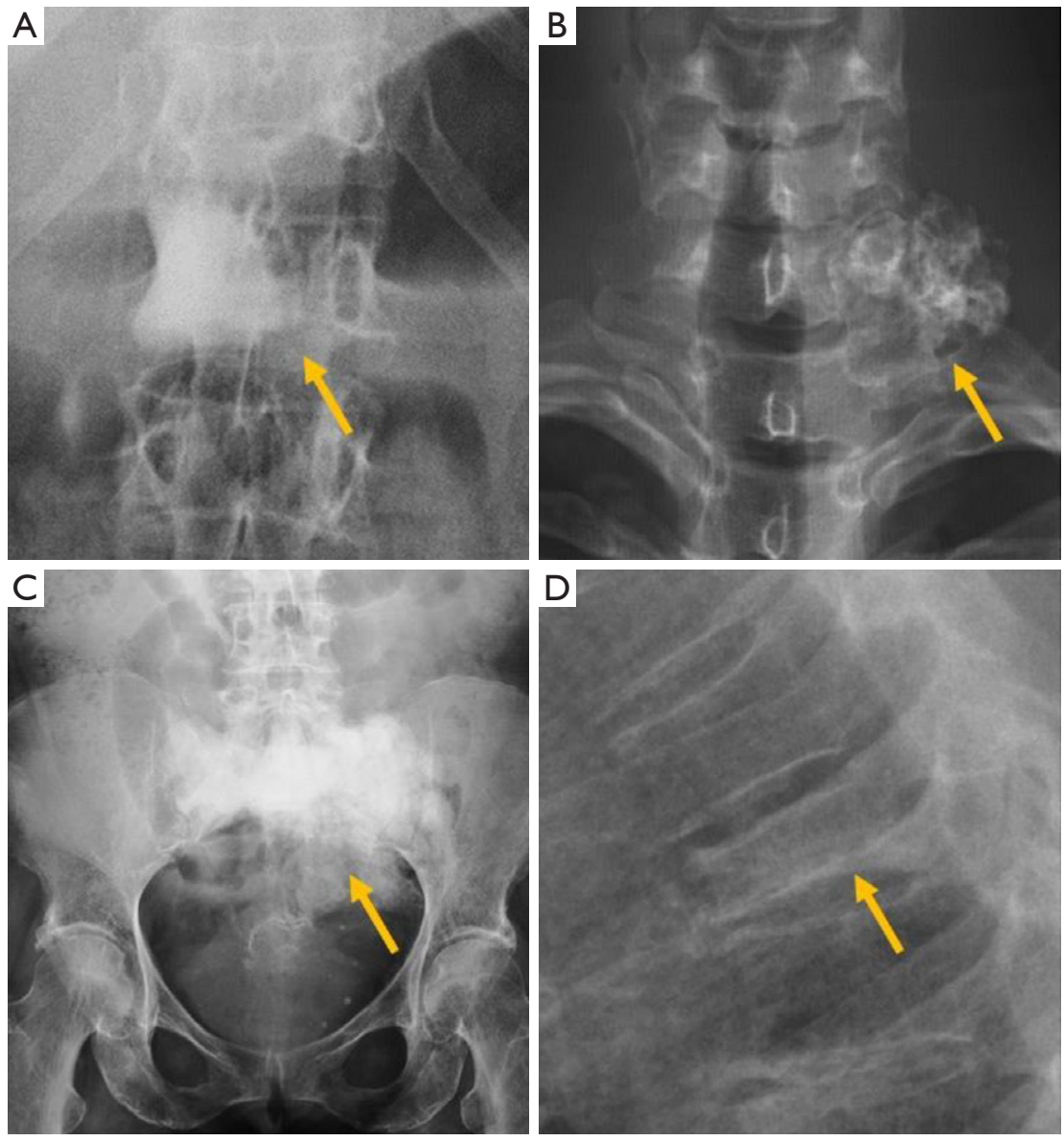

Figure 30 Primary sclerotic tumours and pseudotumours of the spine. (A) Bone island; (B) osteochondroma; (C) sacral osteosarcoma; (D) sclerotic fracture in lymphoma. Arrows point the main abnormality in each case.

the tumour matrix, with marked mineralisation originating in the vertebral body that may manifest as an "ivory vertebra" (144). This sclerotic vertebra can also be seen in bone lymphoma (Figure 30).

Solitary plasmacytoma is an uncommon tumour that occurs in $3-7 \%$ of patients with plasma cell neoplasms. It is considered to represent the early stages of multiple myeloma $(\mathrm{MM})$ and shows a predominantly lytic pattern (153). Bone disease in multiple myeloma patients is characterised by lytic bone lesions that can result in pathologic fractures and severe pain $(154,155)$. Between $10 \%$ and $20 \%$ of patients with MM appear normal on radiography $(156,157)$. Osteopenia and osteolytic lesions may present separately or in association. Vertebral fractures have been reported in $50-70 \%$ of patients with MM $(158,159)$. It is noteworthy to know that the radiographic appearance of MM may resemble that of OVFs, and the topographic distribution of the fractures is similar in both cases (158) (Figure 31).

\section{Conclusions}

Radiographs are still useful in assessing the anatomy and pathology of the spine in many clinical settings. The take-home messages are the following: (I) panoramic view of the whole spine is essential in assessing coronal alignment and sagittal balance after fracture, in congenital or developmental abnormalities with associated deformity (scoliosis and kyphosis), or in deformity secondary to degenerative disorders; (II) comparison of standing radiographs with supine radiographs or CT are useful in assessing unstable OVFs; (III) degenerative, inflammatory and tumour pathology can be characterised on radiographs with different degrees of sensitivity. 

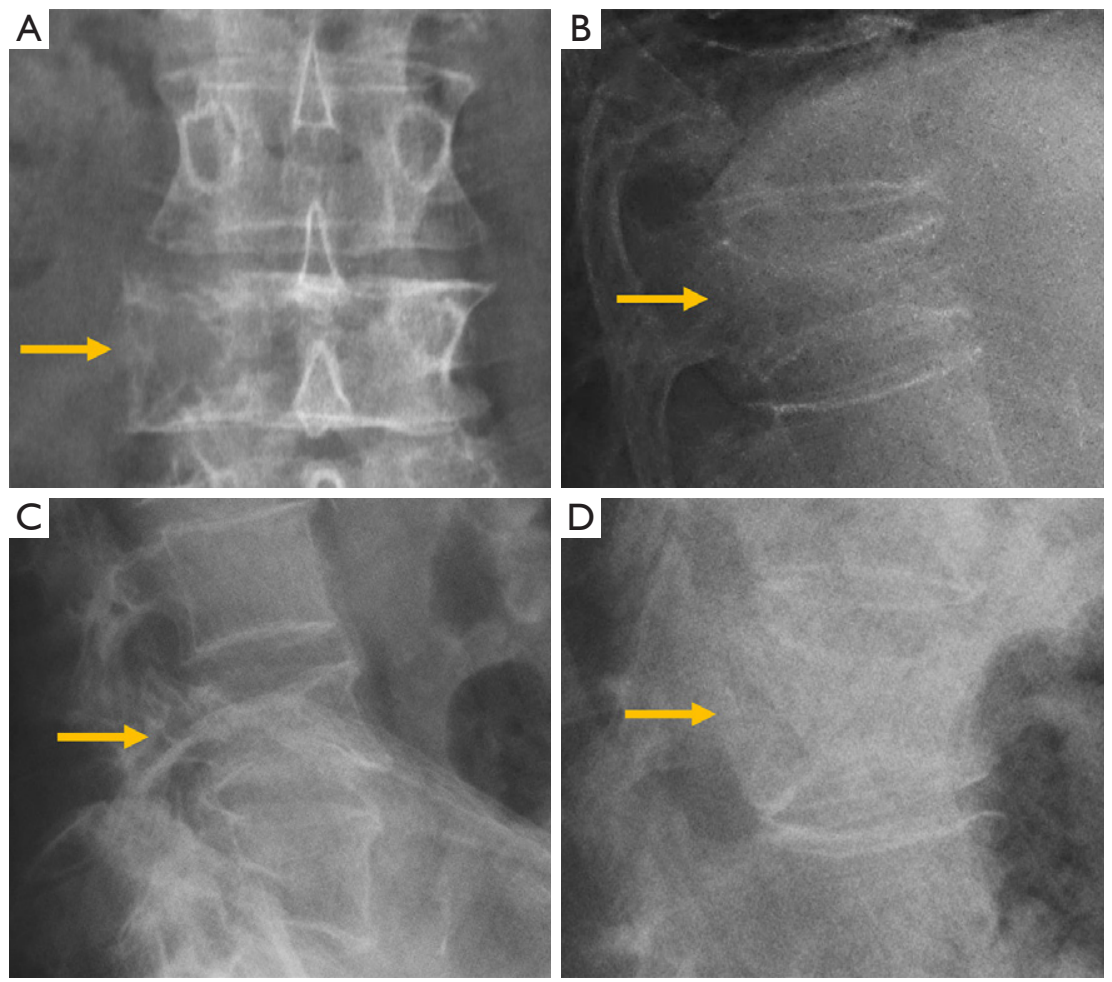

Figure 31 Vertebral involvement of myeloma in different patients. (A) “One-eyed vertebra" sign in myeloma. Burst (B), biconcave (C) and wedge fractures $(\mathrm{D})$ in multiple myeloma. Arrows point the main abnormality in each case.

\section{Acknowledgments}

Funding: None.

\section{Footnote}

Conflicts of Interest: All authors have completed the ICMJE uniform disclosure form (available at http://dx.doi. org/10.21037/qims-20-1014). YXJW serves as unpaid Editor-In-Chief of Quantitative Imaging in Medicine and Surgery. The other authors have no conflicts of interest to declare.

Open Access Statement: This is an Open Access article distributed in accordance with the Creative Commons Attribution-NonCommercial-NoDerivs 4.0 International License (CC BY-NC-ND 4.0), which permits the noncommercial replication and distribution of the article with the strict proviso that no changes or edits are made and the original work is properly cited (including links to both the formal publication through the relevant DOI and the license). See: https://creativecommons.org/licenses/by-nc-nd/4.0/.

\section{References}

1. Deyo RA, Weinstein JN. Low back pain. N Engl J Med 2001;344:363-70.

2. Wáng YXJ, Wu AM, Ruiz Santiago F, Nogueira-Barbosa MH. Informed appropriate imaging for low back pain management: A narrative review. J Orthop Translat 2018;15:21-34.

3. Patel ND, Broderick DF, Burns J, Deshmukh TK, Fries IB, Harvey HB, Holly L, Hunt CH, Jagadeesan BD, Kennedy TA, O'Toole JE, Perlmutter JS, Policeni B, Rosenow JM, Schroeder JW, Whitehead MT, Cornelius RS, Corey AS. ACR Appropriateness Criteria Low Back Pain. J Am Coll Radiol 2016;13:1069-78.

4. Schlemmer E, Mitchiner JC, Brown M, Wasilevich E. Imaging during low back pain ED visits: a claims-based descriptive analysis. Am J Emerg Med 2015;33:414-8.

5. Ramirez N, Flynn JM, Hill BW, Serrano JA, Calvo CE, Bredy R, Macchiavelli RE. Evaluation of a systematic approach to pediatric back pain: the utility of magnetic resonance imaging. J Pediatr Orthop 2015;35:28-32.

6. Expert Panel on Pediatric Imaging:, Booth TN, Iyer 
RS, Falcone RA Jr, Hayes LL, Jones JY, Kadom N, Kulkarni AV, Myseros JS, Partap S, Reitman C, Robertson RL, Ryan ME, Saigal G, Soares BP, Tekes-Brady A, Trout AT, Zumberge NA, Coley BD, Palasis S. ACR Appropriateness Criteria ${ }^{\circledR}$ Back Pain-Child. J Am Coll Radiol 2017;14:S13-S24.

7. Bhatia NN, Chow G, Timon SJ, Watts HG. Diagnostic modalities for the evaluation of pediatric back pain: a prospective study. J Pediatr Orthop 2008;28:230-3.

8. Feldman DS, Straight JJ, Badra MI, Mohaideen A, Madan SS. Evaluation of an algorithmic approach to pediatric back pain. J Pediatr Orthop 2006;26:353-7.

9. Miller R, Beck NA, Sampson NR, Zhu X, Flynn JM, Drummond D. Imaging modalities for low back pain in children: a review of spondyloysis and undiagnosed mechanical back pain. J Pediatr Orthop 2013;33:282-8.

10. Chaturvedi A, Klionsky NB, Nadarajah U, Chaturvedi A, Meyers SP. Malformed vertebrae: a clinical and imaging review. Insights Imaging 2018;9:343-55.

11. McMaster MJ. Spinal growth and congenital deformity of the spine. Spine (Phila Pa 1976) 2006;31:2284-7.

12. Nguyen VD, Tyrrel R. Klippel-Feil syndrome: patterns of bony fusion and wasp-waist sign. Skeletal Radiol 1993;22:519-23.

13. Vázquez-López ME, López-Conde MI, Somoza-Rubio C, Pérez-Pacín R, Morales-Redondo R, González-Gay MA. Anomalies of vertebrae and ribs: Jarcho Levin syndrome. Description of a case and literature review. Joint Bone Spine 2005;72:275-7.

14. Zhou PL, Poorman GW, Wang C, Pierce KE, Bortz CA, Alas H, Brown AE, Tishelman JC, Janjua MB, VasquezMontes D, Moon J, Horn SR, Segreto F, Ihejirika YU, Diebo BG, Passias PG. Klippel-Feil: A constellation of diagnoses, a contemporary presentation, and recent national trends. J Craniovertebr Junction Spine 2019;10:133-8.

15. McMaster MJ, Singh H. Natural history of congenital kyphosis and kyphoscoliosis. A study of one hundred and twelve patients. J Bone Joint Surg Am 1999;81:1367-83.

16. Expert Panel on Pediatric Imaging:, Jones JY, Saigal G, Palasis S, Booth TN, Hayes LL, Iyer RS, Kadom N, Kulkarni AV, Milla SS, Myseros JS, Reitman C, Robertson RL, Ryan ME, Schulz J, Soares BP, Tekes A, Trout AT, Karmazyn B. ACR Appropriateness Criteria ${ }^{\circledR}$ ScoliosisChild. J Am Coll Radiol 2019;16:S244-S251.

17. Belmont PJ Jr, Kuklo TR, Taylor KF, Freedman BA, Prahinski JR, Kruse RW. Intraspinal anomalies associated with isolated congenital hemivertebra: the role of routine magnetic resonance imaging. J Bone Joint Surg Am 2004;86:1704-10.

18. Trenga AP, Singla A, Feger MA, Abel MF. Patterns of congenital bony spinal deformity and associated neural anomalies on $\mathrm{X}$-ray and magnetic resonance imaging. $\mathrm{J}$ Child Orthop 2016;10:343-52.

19. Wu ZX, Huang LY, Sang HX, Ma ZS, Wan SY, Cui G, Lei $\mathrm{W}$. Accuracy and safety assessment of pedicle screw placement using the rapid prototyping technique in severe congenital scoliosis. J Spinal Disord Tech 2011;24:444-50.

20. Ruiz Santiago F, Guzmán Alvarez L, Tello Moreno M, Navarrete González PJ. Plain-film radiography in the study of spinal pain. Radiologia 2010;52:126-37.

21. Uçar D, Uçar BY, Coşar Y, Emrem K, Gümüşsuyu G, Mutlu S, Mutlu B, Caçan MA, Mertsoy Y, Gümüş $H$. Retrospective cohort study of the prevalence of lumbosacral transitional vertebra in a wide and wellrepresented population. Arthritis 2013;2013:461425.

22. Konin GP, Walz DM. Lumbosacral transitional vertebrae: classification, imaging findings, and clinical relevance. AJNR Am J Neuroradiol 2010;31:1778-86.

23. Ortega Herrera R, Ruiz Santiago F, Cañadillas Barea L, Galera L. Elongation of the anterior tubercle of the cervical vertebral transverse process. Radiología 1999;41:531-3.

24. Expert Panel on Neurological Imaging and Musculoskeletal Imaging:, Beckmann NM, West OC, Nunez D Jr, Kirsch CFE, Aulino JM, Broder JS, Cassidy RC, Czuczman GJ, Demertzis JL, Johnson MM, Motamedi K, Reitman C, Shah LM, Than K, Ying-Kou Yung E, Beaman FD, Kransdorf MJ, Bykowski J. ACR Appropriateness Criteria ${ }^{\circledR}$ Suspected Spine Trauma. J Am Coll Radiol 2019;16:S264-S285.

25. Bailitz J, Starr F, Beecroft M, Bankoff J, Roberts R, Bokhari F, Joseph K, Wiley D, Dennis A, Gilkey S, Erickson P, Raksin P, Nagy K. CT should replace threeview radiographs as the initial screening test in patients at high, moderate, and low risk for blunt cervical spine injury: a prospective comparison. J Trauma 2009;66:1605-9.

26. Griffen MM, Frykberg ER, Kerwin AJ, Schinco MA, Tepas JJ, Rowe K, Abboud J. Radiographic clearance of blunt cervical spine injury: plain radiograph or computed tomography scan? J Trauma 2003;55:222-6; discussion 226-7.

27. Veiga JRS, Mitchell K. Cervical spine clearance in the adult obtunded blunt trauma patient: A systematic review. Intensive Crit Care Nurs 2019;51:57-63.

28. Duane TM, Young AJ, Vanguri P, Wolfe LG, Katzen J, Han J, Mayglothling J, Whelan JF, Aboutanos MB, 
Ivatury RR, Malhotra AK. Defining the cervical spine clearance algorithm: A single-institution prospective study of more than 9,000 patients. J Trauma Acute Care Surg 2016;81:541-7.

29. Hoffman JR, Mower WR, Wolfson AB, Todd KH, Zucker MI. Validity of a set of clinical criteria to rule out injury to the cervical spine in patients with blunt trauma. National Emergency X-Radiography Utilization Study Group. N Engl J Med 2000;343:94-9.

30. Stiell IG, Wells GA, Vandemheen KL, Clement CM, Lesiuk H, De Maio VJ, Laupacis A, Schull M, McKnight RD, Verbeek R, Brison R, Cass D, Dreyer J, Eisenhauer MA, Greenberg GH, MacPhail I, Morrison L, Reardon M, Worthington J. The Canadian C-spine rule for radiography in alert and stable trauma patients. JAMA 2001;286:1841-8.

31. Peetz AB, Salim A. Clearance of the Spine. Curr Trauma Rep 2015;1:160-8.

32. Sliker CW, Mirvis SE, Shanmuganathan K. Assessing cervical spine stability in obtunded blunt trauma patients: review of medical literature. Radiology 2005;234:733-9.

33. Karul M, Bannas P, Schoennagel BP, Hoffmann A, Wedegaertner U, Adam G, Yamamura J. Fractures of the thoracic spine in patients with minor trauma: comparison of diagnostic accuracy and dose of biplane radiography and MDCT. Eur J Radiol 2013;82:1273-7.

34. Rhea JT, Sheridan RL, Mullins ME, Novelline RA. Can chest and abdominal trauma CT eliminate the need for plain films of the spine? - Experience with 329 multiple trauma patients. Emergency Radiology 2001;8:99-104.

35. Sheridan R, Peralta R, Rhea J, Ptak T, Novelline R. Reformatted visceral protocol helical computed tomographic scanning allows conventional radiographs of the thoracic and lumbar spine to be eliminated in the evaluation of blunt trauma patients. J Trauma 2003;55:665-9.

36. Ballock RT, Mackersie R, Abitbol JJ, Cervilla V, Resnick D, Garfin SR. Can burst fractures be predicted from plain radiographs? J Bone Joint Surg Br 1992;74:147-50.

37. Melton LJ 3rd. Epidemiology of spinal osteoporosis. Spine (Phila Pa 1976) 1997;22:2S-11S.

38. Wáng YX, Lentle BC. Radiographic osteoporotic vertebral fractures in elderly men: a brief review focusing on differences between the sexes. Quant Imaging Med Surg 2020;10:1863-76.

39. Weaver J, Sajjan S, Lewiecki EM, Harris ST, Marvos P. Prevalence and Cost of Subsequent Fractures Among U.S. Patients with an Incident Fracture. J Manag Care Spec
Pharm 2017;23:461-71.

40. Delmas PD, Genant HK, Crans GG, Stock JL, Wong M, Siris E, Adachi JD. Severity of prevalent vertebral fractures and the risk of subsequent vertebral and nonvertebral fractures: results from the MORE trial. Bone 2003;33:522-32.

41. Sanchez-Rodriguez D, Bergmann P, Body JJ, Cavalier E, Gielen E, Goemaere S, Lapauw B, Laurent MR, Rozenberg S, Honvo G, Beaudart C, Bruyère O. The Belgian Bone Club 2020 guidelines for the management of osteoporosis in postmenopausal women. Maturitas 2020;139:69-89.

42. Danila MI, Saag KG. Imminent Fracture Risk: A Call to Action for Rheumatologists. Arthritis Care Res (Hoboken) 2020;72:741-3.

43. Nuti R, Brandi ML, Checchia G, Di Munno O, Dominguez L, Falaschi P, Fiore CE, Iolascon G, Maggi S, Michieli R, Migliaccio S, Minisola S, Rossini M, Sessa G, Tarantino U, Toselli A, Isaia GC. Guidelines for the management of osteoporosis and fragility fractures. Intern Emerg Med 2019;14:85-102.

44. Singer A, Exuzides A, Spangler L, O'Malley C, Colby C, Johnston K, Agodoa I, Baker J, Kagan R. Burden of illness for osteoporotic fractures compared with other serious diseases among postmenopausal women in the United States. Mayo Clin Proc 2015;90:53-62.

45. Crandall CJ, Newberry SJ, Diamant A, Lim YW, Gellad WF, Booth MJ, Motala A, Shekelle PG. Comparative effectiveness of pharmacologic treatments to prevent fractures: an updated systematic review. Ann Intern Med 2014;161:711-23.

46. Viswanathan M, Reddy S, Berkman N, Cullen K, Middleton JC, Nicholson WK, Kahwati LC. Screening to prevent osteoporotic fractures: updated evidence report and systematic review for the US preventive services task force. JAMA 2018;319:2532-51.

47. Ensrud KE, Blackwell TL, Fink HA, Zhang J, Cauley JA, Cawthon PM, Black DM, Bauer DC, Curtis JR, Orwoll ES, Barrett-Connor E, Kado DM, Marshall LM, Shikany JM, Schousboe JT; Osteoporotic Fractures in Men (MrOS) Research Group. What Proportion of Incident Radiographic Vertebral Fractures in Older Men Is Clinically Diagnosed and Vice Versa: A Prospective Study. J Bone Miner Res 2016;31:1500-3.

48. Fink HA, Milavetz DL, Palermo L, Nevitt MC, Cauley JA, Genant HK, Black DM, Ensrud KE; Fracture Intervention Trial Research Group. What proportion of incident radiographic vertebral deformities is clinically diagnosed 
and vice versa? J Bone Miner Res 2005;20:1216-22.

49. Kim DH, Vaccaro AR. Osteoporotic compression fractures of the spine; current options and considerations for treatment. Spine J 2006;6:479-87.

50. Messina C, Maffi G, Vitale JA, Ulivieri FM, Guglielmi G, Sconfienza LM. Diagnostic imaging of osteoporosis and sarcopenia: a narrative review. Quant Imaging Med Surg 2018;8:86-99.

51. Rosen HN, Vokes TJ, Malabanan AO, Deal CL, Alele JD, Olenginski TP, Schousboe JT. The Official Positions of the International Society for Clinical Densitometry: vertebral fracture assessment. J Clin Densitom 2013;16:482-8.

52. Jiang G, Eastell R, Barrington NA, Ferrar L. Comparison of methods for the visual identification of prevalent vertebral fracture in osteoporosis. Osteoporos Int 2004;15:887-96.

53. Lunt M, Felsenberg D, Reeve J, Benevolenskaya L, Cannata J, Dequeker J, Dodenhof C, Falch JA, Masaryk P, Pols HA, Poor G, Reid DM, Scheidt-Nave C, Weber K, Varlow J, Kanis JA, O'Neill TW, Silman AJ. Bone density variation and its effects on risk of vertebral deformity in men and women studied in thirteen European centers: the EVOS Study. J Bone Miner Res 1997;12:1883-94.

54. Wáng YXJ, Che-Nordin N, Leung JCS, Kwok TCY. Existing severe osteoporotic vertebral fractures in elderly Chinese males were only weakly associated with higher further vertebral fracture risk at year-4 follow-up. Osteoporos Int 2020;31:1593-4.

55. Wang XR, Xu FR, Huang QL, Wáng YXJ. Radiological features of traumatic vertebral endplate fracture: an analysis of 194 cases with 263 vertebral fractures. Chin Med J (Engl) 2020. [Epub ahead of print]. doi: 10.1097/ CM9.0000000000000919.

56. Sugita M, Watanabe N, Mikami Y, Hase H, Kubo T. Classification of vertebral compression fractures in the osteoporotic spine. J Spinal Disord Tech 2005;18:376-81.

57. Ha KY, Kim YH. Risk factors affecting progressive collapse of acute osteoporotic spinal fractures. Osteoporos Int 2013;24:1207-13.

58. Lentle BC, Berger C, Probyn L, Brown JP, Langsetmo L, Fine B, Lian K, Shergill AK, Trollip J, Jackson S, Leslie WD, Prior JC, Kaiser SM, Hanley DA, Adachi JD, Towheed T, Davison KS, Cheung AM, Goltzman D; CaMos Research Group. Comparative Analysis of the Radiology of Osteoporotic Vertebral Fractures in Women and Men: Cross-Sectional and Longitudinal Observations from the Canadian Multicentre Osteoporosis Study (CaMos). J Bone Miner Res 2018;33:569-79.
59. Schnake KJ, Blattert TR, Hahn P, Franck A, Hartmann F, Ullrich B, Verheyden A, Mörk S, Zimmermann V, Gonschorek O, Müller M, Katscher S, Saman AE, Pajenda G, Morrison R, Schinkel C, Piltz S, Partenheimer A, Müller CW, Gercek E, Scherer M, Bouzraki N, Kandziora F; Spine Section of the German Society for Orthopaedics and Trauma. Classification of Osteoporotic Thoracolumbar Spine Fractures: Recommendations of the Spine Section of the German Society for Orthopaedics and Trauma (DGOU). Global Spine J 2018;8:46S-49S.

60. Blattert TR, Schnake KJ, Gonschorek O, Gercek E, Hartmann F, Katscher S, Mörk S, Morrison R, Müller M, Partenheimer A, Piltz S, Scherer MA, Ullrich BW, Verheyden A, Zimmermann V; Spine Section of the German Society for Orthopaedics and Trauma. Nonsurgical and Surgical Management of Osteoporotic Vertebral Body Fractures: Recommendations of the Spine Section of the German Society for Orthopaedics and Trauma (DGOU). Global Spine J 2018;8:50S-55S.

61. Genant HK, Wu CY, van Kuijk C, Nevitt MC. Vertebral fracture assessment using a semiquantitative technique. J Bone Miner Res 1993;8:1137-48.

62. Wáng YXJ, Che-Nordin N. Informed communication with study subjects of radiographically detected osteoporotic vertebral deformity. Quant Imaging Med Surg 2018;8:876-80.

63. Wáng YXJ, Diacinti D, Yu W, Cheng XG, NogueiraBarbosa MH, Che-Nordin N, Guglielmi G, Ruiz Santiago F. Semi-quantitative grading and extended semiquantitative grading for osteoporotic vertebral deformity: a radiographic image database for education and calibration. Ann Transl Med 2020;8:398.

64. Wáng YXJ, Che-Nordin N, Deng M, Leung JCS, Kwok AWL, He LC, Griffith JF, Kwok TCY, Leung PC. Osteoporotic vertebral deformity with endplate/cortex fracture is associated with higher further vertebral fracture risk: the Ms. OS (Hong Kong) study results. Osteoporos Int 2019;30:897-905.

65. Wáng YXJ. A modified semi-quantitative (mSQ) grading scheme for osteoporotic vertebral fracture in elderly women. Quant Imaging Med Surg 2019;9:146-50.

66. Lentle B, Trollip J, Lian K. The Radiology of Osteoporotic Vertebral Fractures Redux. J Clin Densitom 2016;19:40-7.

67. Deng M, Kwok TCY, Leung JCS, Leung PC, Wáng YXJ. All osteoporotically deformed vertebrae with $>34 \%$ height loss have radiographically identifiable endplate/cortex fracture. J Orthop Translat 2018;14:63-6.

68. Guggina P, Flahive J, Hooven FH, Watts NB, Siris ES, 
Silverman S, Roux C, Pfeilschifter J, Greenspan SL, Díez-Pérez A, Cooper C, Compston JE, Chapurlat R, Boonen S, Adachi JD, Anderson FA Jr, Gehlbach S; GLOW Investigators. Characteristics associated with anti-osteoporosis medication use: data from the Global Longitudinal Study of Osteoporosis in Women (GLOW) USA cohort. Bone 2012;51:975-80.

69. Delmas PD, van de Langerijt L, Watts NB, Eastell R, Genant H, Grauer A, Cahall DL; IMPACT Study Group. Underdiagnosis of vertebral fractures is a worldwide problem: the IMPACT study. J Bone Miner Res 2005;20:557-63.

70. Bartalena T, Rinaldi MF, Modolon C, Braccaioli L, Sverzellati N, Rossi G, Rimondi E, Busacca M, Albisinni $\mathrm{U}$, Resnick D. Incidental vertebral compression fractures in imaging studies: Lessons not learned by radiologists. World J Radiol 2010;2:399-404.

71. Wáng YXJ, Che-Nordin N. Some radiographically 'occult' osteoporotic vertebral fractures can be evidential if we look carefully. Quant Imaging Med Surg 2019;9:1992-5.

72. Wáng YXJ, Du MM, Che-Nordin N, Ye PP, Qiu SW, Griffith JF, Yan ZH. Recognizing osteoporotic vertebral deformity on frontal view radiograph: a cohort analysis and a pictorial review. Arch Osteoporos 2020;15:41.

73. Matzaroglou C, Georgiou CS, Panagopoulos A, Assimakopoulos K, Wilke HJ, Habermann B, Panos G, Kafchitsas K. Kümmell's Disease: Clarifying the Mechanisms and Patients' Inclusion Criteria Open. Orthop J 2014;8:288-97.

74. Venmans A, Klazen CA, Lohle PN, Mali WP, van Rooij WJ. Natural history of pain in patients with conservatively treated osteoporotic vertebral compression fractures: results from VERTOS II. AJNR Am J Neuroradiol 2012;33:519-21.

75. Cho JH, Shin SI, Lee JH, Yeom JS, Chang BS, Lee CK. Usefulness of prone cross-table lateral radiographs in vertebral compression fractures. Clin Orthop Surg 2013;5:195-201.

76. McKiernan F, Jensen R, Faciszewski T. The dynamic mobility of vertebral compression fractures. J Bone Miner Res 2003;18:24-9.

77. Lim J, Choi SW, Youm JY, Kwon HJ, Kim SH, Koh HS. Posttraumatic Delayed Vertebral Collapse : Kummell's Disease. J Korean Neurosurg Soc 2018;61:1-9.

78. Nakamae T, Fujimoto Y, Yamada K, Hashimoto T, Olmarker K. Efficacy of Percutaneous Vertebroplasty in the Treatment of Osteoporotic Vertebral Compression Fractures with Intravertebral Cleft. Open Orthop J
2015;9:107-13.

79. Wáng YXJ, Santiago FR, Deng M, Nogueira-Barbosa MH. Identifying osteoporotic vertebral endplate and cortex fractures. Quant Imaging Med Surg 2017;7:555-91.

80. Pathria M, Sartoris DJ, Resnick D. Osteoarthritis of the facet joints: accuracy of oblique radiographic assessment. Radiology 1987;164:227-30.

81. Resnick D. Degenerative disease of the vertebral column. Radiology 1985;156:3-14.

82. Jensen MC, Brant-Zawadzki MN, Obuchowski N, Modic MT, Malkasian D, Ross JS. Magnetic resonance imaging of the lumbar spine in people without back pain. $\mathrm{N}$ Engl J Med 1994;331:69-73.

83. Milette PC. The proper terminology for reporting lumbar intervertebral disk disorders. AJNR Am J Neuroradiol 1997;18:1859-66.

84. Mader R, Verlaan JJ, Eshed I, Bruges-Armas J, Puttini PS, Atzeni F, Buskila D, Reinshtein E, Novofastovski I, Fawaz A, Kurt V, Baraliakos X. Diffuse idiopathic skeletal hyperostosis (DISH): where we are now and where to go next. RMD Open 2017;3:e000472.

85. Utsinger PD. Diffuse idiopathic skeletal hyperostosis. Clin Rheum Dis 1985;11:325-51.

86. Buckle CE, Udawatta V, Straus CM. Now You See It, Now You Don't: Visual Illusions in Radiology. RadioGraphics 2013; 33:2087-102.

87. Gallucci M, Limbucci N, Paonessa A, Splendiani A. Degenerative disease of the spine. Neuroimaging Clin $\mathrm{N}$ Am 2007;17:87-103.

88. Leone A, Guglielmi G, Cassar-Pullicino VN, Bonomo L. Lumbar intervertebral instability: a review. Radiology 2007;245:62-77.

89. Jiang SD, Jiang LS, Dai LY. Degenerative cervical spondylolisthesis: a systematic review. Int Orthop 2011;35:869-75.

90. Fielding JW, Cochran Gv, Lawsing JF 3rd, Hohl M. Tears of the transverse ligament of the atlas. A clinical and biomechanical study. J Bone Joint Surg Am 1974;56:1683-91.

91. Meyerding HW. Spondylolisthesis. Surgical, Gynecology, \& Obstetrics 1932;54:371-7.

92. Wáng YX, Deng M, Griffith JF, Kwok AW, Leung JC, Ahuja AT, Kwok T, Leung PC. Lumbar Spondylolisthesis Progression and De Novo Spondylolisthesis in Elderly Chinese Men and Women: A Year-4 Follow-up Study. Spine (Phila Pa 1976) 2016;41:1096-103.

93. Amato M, Totty WG, Gilula LA. Spondylolysis of the lumbar spine: demonstration of defects and laminal 
fragmentation. Radiology 1984;153:627-9.

94. Libson E, Bloom RA, Dinari G. Symptomatic and asymptomatic spondylolysis and spondylolisthesis in young adults. Int Orthop 1982;6:259-61.

95. Schmid T, Heini P, Benneker L. A rare case of nontraumatic, multi-level, bilateral pedicle fractures of the lumbar spine in a 60-year-old patient. Eur Spine J 2017;26:197-201.

96. Hu SS, Tribus CB, Diab M, Ghanayem AJ. Spondylolisthesis and spondylolysis. J Bone Joint Surg Am 2008;90:656-71.

97. He LC, Wang YX, Gong JS, Griffith JF, Zeng XJ, Kwok AW, Leung JC, Kwok T, Ahuja AT, Leung PC. Prevalence and risk factors of lumbar spondylolisthesis in elderly Chinese men and women. Eur Radiol 2014;24:441-8.

98. Wang YXJ, Káplár Z, Deng M, Leung JCS. Lumbar degenerative spondylolisthesis epidemiology: A systematic review with a focus on gender-specific and age-specific prevalence. J Orthop Translat 2016;11:39-52.

99. Fon GT, Pitt MJ, Thies AC Jr. Thoracic kyphosis: range in normal subjects. AJR Am J Roentgenol 1980;134:979-83.

100. Vialle R, Levassor N, Rillardon L, Templier A, Skalli W, Guigui P. Radiographic analysis of the sagittal alignment and balance of the spine in asymptomatic subjects. J Bone Joint Surg Am 2005;87:260-7.

101.Jackson RP, McManus AC. Radiographic analysis of sagittal plane alignment and balance in standing volunteers and patients with low back pain matched for age, sex, and size: a prospective controlled clinical study. Spine (Phila $\mathrm{Pa}$ 1976) 1994;19:1611-8.

102. Boyle JJ, Milne N, Singer KP. Influence of age on cervicothoracic spinal curvature: an ex vivo radiographic survey. Clin Biomech (Bristol, Avon) 2002;17:361-7.

103. Kado DM, Prenovost K, Crandall C. Narrative review: hyperkyphosis in older persons. Ann Intern Med 2007;147:330-8.

104. Ohrt-Nissen S, Cheung JPY, Hallager DW, Gehrchen M, Kwan K, Dahl B, Cheung KMC, Samartzis D. Reproducibility of thoracic kyphosis measurements in patients with adolescent idiopathic scoliosis. Scoliosis Spinal Disord 2017;12:4.

105.Kyrölä KK, Salme J, Tuija J, Tero I, Eero K, Arja H. Intra- and Interrater Reliability of Sagittal Spinopelvic Parameters on Full-Spine Radiographs in Adults With Symptomatic Spinal Disorders. Neurospine 2018;15:175-81.

106. Sachs B, Bradford D, Winter R, Lonstein J, Moe J, Willson S. Scheuermann kyphosis. Follow-up of Milwaukee-brace treatment. J Bone Joint Surg Am 1987;69:50-7.

107. Sørensen KH. Scheuermann's juvenile kyphosis. København: Munksgaard 1964:222-4

108. Farsetti P, Tudisco C, Caterini R, Ippolito E. Juvenile and idiopathic kyphosis. Long-term follow-up of 20 cases. Arch Orthop Trauma Surg 1991;110:165-8.

109. Gaca AM, Barnhart HX, Bisset GS 3rd. Evaluation of wedging of lower thoracic and upper lumbar vertebral bodies in the pediatric population. AJR Am J Roentgenol 2010;194:516-20.

110.Masharawi Y, Salame K, Mirovsky Y, Peleg S, Dar G, Steinberg N, Hershkovitz I. Vertebral body shape variation in the thoracic and lumbar spine: characterization of its asymmetry and wedging. Clin Anat 2008;21:46-54.

111.Been E, Kalichman L. Lumbar lordosis. Spine J 2014;14:87-97.

112. Gelb DE, Lenke LG, Bridwell KH, Blanke K, McEnery KW. An analysis of sagittal spinal alignment in 100 asymptomatic middle and older aged volunteers. Spine (Phila Pa 1976) 1995;20:1351-8.

113. Kuntz C 4th, Levin LS, Ondra SL, Shaffrey CI, Morgan CJ. Neutral upright sagittal spinal alignment from the occiput to the pelvis in asymptomatic adults: a review and resynthesis of the literature. J Neurosurg Spine 2007;6:104-12.

114. Le Huec JC, Thompson W, Mohsinaly Y, Barrey C, Faundez A. Sagittal balance of the spine. Eur Spine J 2019;28:1889-905.

115.Diebo BG, Varghese JJ, Lafage R, Schwab FJ, Lafage V. Sagittal alignment of the spine: What do you need to know? Clin Neurol Neurosurg 2015;139:295-301.

116. Schwab F, Patel A, Ungar B, Farcy JP, Lafage V. Adult spinal deformity-postoperative standing imbalance: how much can you tolerate? An overview of key parameters in assessing alignment and planning corrective surgery. Spine (Phila Pa 1976) 2010;35:2224-31.

117. Glassman SD, Berven S, Bridwell K, Horton W, Dimar JR. Correlation of radiographic parameters and clinical symptoms in adult scoliosis. Spine (Phila Pa 1976) 2005;30:682-8.

118. Sud A, Tsirikos AI. Current concepts and controversies on adolescent idiopathic scoliosis: Part I. Indian J Orthop 2013;47:117-28.

119. Tanure MC, Pinheiro AP, Oliveira AS. Reliability assessment of Cobb angle measurements using manual and digital methods. Spine J 2010;10:769-74.

120. Gstoettner M, Sekyra K, Walochnik N, Winter P, Wachter $\mathrm{R}$, Bach CM. Inter- and intraobserver reliability assessment 
of the Cobb angle: manual versus digital measurement tools. Eur Spine J 2007;16:1587-92.

121.Lenke LG, Edwards CC 2nd, Bridwell KH. The Lenke classification of adolescent idiopathic scoliosis: how it organizes curve patterns as a template to perform selective fusions of the spine. Spine (Phila Pa 1976) 2003;28:S199-207.

122. Buchowski JM, Kuhns CA, Bridwell KH, Lenke LG. Surgical management of posttraumatic thoracolumbar kyphosis. Spine J 2008;8:666-77.

123. Lowe T, Berven SH, Schwab FJ, Bridwell KH. The SRS classification for adult spinal deformity: building on the King/Moe and Lenke classification systems. Spine (Phila Pa 1976) 2006;31:S119-25.

124. Bao H, Yan P, Qiu Y, Liu Z, Zhu F. Coronal imbalance in degenerative lumbar scoliosis: Prevalence and influence on surgical decision-making for spinal osteotomy. Bone Joint J 2016;98-B:1227-33.

125.Plais N, Bao H, Lafage R, Gupta M, Smith JS, Shaffrey C, Mundis G, Burton D, Ames C, Klineberg E, Bess S, Schwab F, Lafage V; International Spine Study Group. The clinical impact of global coronal malalignment is underestimated in adult patients with thoracolumbar scoliosis. Spine Deform 2020;8:105-13.

126.Jurik AG. Imaging the spine in arthritis-a pictorial review. Insights Imaging 2011;2:177-91.

127. Rudwaleit M, van der Heijde D, Landewé R, Listing J, Akkoc N, Brandt J, Braun J, Chou CT, Collantes-Estevez E, Dougados M, Huang F, Gu J, Khan MA, Kirazli Y, Maksymowych WP, Mielants H, Sørensen IJ, Ozgocmen S, Roussou E, Valle-Oñate R, Weber U, Wei J, Sieper $\mathrm{J}$. The development of Assessment of SpondyloArthritis international Society classification criteria for axial spondyloarthritis (part II): validation and final selection. Ann Rheum Dis 2009;68:777-83.

128. Proft F, Poddubnyy D. Ankylosing spondylitis and axial spondyloarthritis: recent insights and impact of new classification criteria. Ther Adv Musculoskelet Dis 2018;10:129-39.

129. Tsoi C, Griffith JF, Lee RKK, Wong PCH, Tam LS. Imaging of sacroiliitis: Current status, limitations and pitfalls. Quant Imaging Med Surg 2019;9:318-35.

130. Malaviya AN, Rawat R, Agrawal N, Patil NS. The Nonradiographic Axial Spondyloarthritis, the Radiographic Axial Spondyloarthritis, and Ankylosing Spondylitis: The Tangled Skein of Rheumatology. Int J Rheumatol 2017;2017:1824794.

131. Braun J, Sieper J, Bollow M. Imaging of sacroiliitis. Clin
Rheumatol 2000;19:51-7.

132.van Tubergen A, Heuft-Dorenbosch L, Schulpen G, Landewé R, Wijers R, van der Heijde D, van Engelshoven J, van der Linden S. Radiographic assessment of sacroiliitis by radiologists and rheumatologists: does training improve quality? Ann Rheum Dis 2003;62:519-25.

133. Guglielmi G, Scalzo G, Cascavilla A, Carotti M, Salaffi F, Grassi W. Imaging of the sacroiliac joint involvement in seronegative spondylarthropathies. Clin Rheumatol 2009;28:1007-19.

134. Muche B, Bollow M, François RJ, Sieper J, Hamm B, Braun J. Anatomic structures involved in early- and latestage sacroiliitis in spondylarthritis: a detailed analysis by contrast-enhanced magnetic resonance imaging. Arthritis Rheum 2003;48:1374-84.

135. Helliwell PS, Hickling P, Wright V. Do the radiological changes of classic ankylosing spondylitis differ from the changes found in the spondylitis associated with inflammatory bowel disease, psoriasis, and reactive arthritis? Ann Rheum Dis 1998;57:135-40.

136.Park WM, Spencer DG, McCall IW, Ward J, Buchanan WW, Stephens WH. The detection of spinal pseudarthrosis in ankylosing spondylitis. Br J Radiol 1981;54:467-72.

137. Feldtkeller E, Vosse D, Geusens P, van der Linden S. Prevalence and annual incidence of vertebral fractures in patients with ankylosing spondylitis. Rheumatol Int 2006;26:234-9.

138. Ogdie A, Harter L, Shin D, Baker J, Takeshita J, Choi HK, Love TJ, Gelfand JM. The risk of fracture among patients with psoriatic arthritis and psoriasis: a populationbased study. Ann Rheum Dis 2017;76:882-5.

139. Younes M, Belghali S, Kriâa S, Zrour S, Bejia I, Touzi M, Golli M, Gannouni A, Bergaoui N. Compared imaging of the rheumatoid cervical spine: prevalence study and associated factors. Joint Bone Spine 2009;76:361-8.

140. Varma R, Lander P, Assaf A. Imaging of pyogenic infectious spondylodiskitis. Radiol Clin North Am 2001;39:203-13.

141. Govender S. Spinal infections. J Bone Joint Surg Br 2005;87:1454-8.

142. Cheung WY, Luk KD. Pyogenic spondylitis. Int Orthop 2012;36:397-404.

143. Teh J, Imam A, Watts C. Imaging of back pain. Imaging 2005;17:171-207.

144. Rodallec MH, Feydy A, Larousserie F, Anract P, Campagna R, Babinet A, Zins M, Drapé JL. Diagnostic imaging of solitary tumors of the spine: what to do and say. 
Radiographics 2008;28:1019-41.

145. Kamholtz R, Sze G. Current imaging in spinal metastatic disease. Semin Oncol 1991;18:158-69.

146.Jacobson AF, Stomper PC, Cronin EB, Kaplan WD. Bone scans with one or two new abnormalities in cancer patients with no known metastases: reliability of interpretation of initial correlative radiographs. Radiology 1990;174:503-7.

147. Algra PR, Heimans JJ, Valk J, Nauta JJ, Lachniet M, Van Kooten B. Do metastases in vertebrae begin in the body or the pedicles? Imaging study in 45 patients. AJR Am J Roentgenol 1992;158:1275-9.

148. Jacobs WB, Perrin RG. Evaluation and treatment of spinal metastases: an overview. Neurosurg Focus 20062001;11:e10.

149. Sham JS, Cheung YK, Chan FL, Choy D. Nasopharyngeal carcinoma: pattern of skeletal metastases. Br J Radiol 1990;63:202-5.

150. Goldman SM, Fajardo AA, Naraval RC, Madewell JE. Metastatic transitional cell carcinoma from the bladder: radiographic manifestions. AJR Am J Roentgenol 1979 ;132:419-25.

151.Kunkler IH, Merrick MV, Rodger A. Bone scintigraphy in breast cancer: a nine-year follow-up. Clin Radiol 1985;36:279-82.

Cite this article as: Ruiz Santiago F, Láinez Ramos-Bossini AJ, Wáng YXJ, López Zúñiga D. The role of radiography in the study of spinal disorders. Quant Imaging Med Surg 2020;10(12):2322-2355. doi: 10.21037/qims-20-1014
152.Price HI, Batnitzky S. The computed tomographic findings in benign diseases of the vertebral column. Crit Rev Diagn Imaging 1985;24:39-89.

153. Murphey MD, Choi JJ, Kransdorf MJ, Flemming DJ, Gannon FH. Imaging of osteochondroma: variants and complications with radiologic-pathologic correlation. Radiographics 2000;20:1407-34.

154.Laredo JD, el Quessar A, Bossard P, Vuillemin-Bodaghi V. Vertebral tumors and pseudotumors. Radiol Clin North Am 2001;39:137-63, vi.

155.Hansford BG, Silbermann R. Advanced Imaging of Multiple Myeloma Bone Disease. Front Endocrinol (Lausanne) 2018;9:436.

156. Collins CD. Multiple myeloma. Cancer Imaging 2004;4 Spec No A:S47-53.

157.Lasocki A, Gaillard F, Harrison SJ. Multiple myeloma of the spine. Neuroradiol J 2017;30:259-68.

158. Lecouvet FE, Vande Berg BC, Michaux L, Jamart J, Maldague BE, Malghem J. Development of vertebral fractures in patients with multiple myeloma: does MRI enable recognition of vertebrae that will collapse? J Comput Assist Tomogr 1998;22:430-6.

159. Spiess JL, Adelstein DJ, Hines JD. Multiple myeloma presenting with spinal cord compression. Oncology 1988;45:88-92. 